\title{
Multi-pollutant emissions from the burning of major agricultural residues in China and the related health-economic effects
}

\author{
Chunlin $\mathrm{Li}^{1}$, Yunjie $\mathrm{Hu}^{1}$, Fei Zhang ${ }^{1}$, Jianmin Chen ${ }^{1,2}$, Zhen $\mathrm{Ma}^{1}$, Xingnan $\mathrm{Ye}^{1}$, Xin Yang ${ }^{1,2}$, Lin Wang ${ }^{1,2}$, \\ Xingfu Tang ${ }^{1}$, Renhe Zhang ${ }^{2}$, Mu Mu ${ }^{2}$, Guihua Wang ${ }^{2}$, Haidong Kan ${ }^{3}$, Xinming Wang ${ }^{4}$, and Abdelwahid Mellouki ${ }^{5}$ \\ ${ }^{1}$ Shanghai Key Laboratory of Atmospheric Particle Pollution and Prevention (LAP ${ }^{3}$ ), Department of Environmental \\ Science \& Engineering, Fudan University, Handan Road 220, Shanghai, 200433, China \\ ${ }^{2}$ Institute of Atmospheric Sciences, Fudan University, Handan Road 220, Shanghai, 200433, China \\ ${ }^{3}$ Public Health School, Fudan University, Dongan Road 120, Shanghai, 200032, China \\ ${ }^{4}$ State Key Lab of Organ Geochemistry, Guangzhou Institute of Geochemistry, Chinese Academy of Sciences, \\ Kehuajie Road 511, Guangzhou, 510640, China \\ ${ }^{5}$ Institut de Combustion, Aérothermique, Réactivité et Environnement, CNRS, 45071 Orléans CEDEX 02, France
}

Correspondence to: Jianmin Chen (jmchen@fudan.edu.cn)

Received: 20 July 2016 - Discussion started: 30 August 2016

Revised: 28 February 2017 - Accepted: 9 March 2017 - Published: 18 April 2017

Abstract. Multi-pollutants in smoke particulate matter (SPM) were identified and quantified for the biomass burning of five major agricultural residues (wheat, rice, corn, cotton, and soybean straw) in China by an aerosol chamber system combined with various measurement techniques. The primary emission factors (EFs) for $\mathrm{PM}_{1.0}$ and $\mathrm{PM}_{2.5}$ are $3.04-12.64$ and $3.25-15.16 \mathrm{~g} \mathrm{~kg}^{-1}$. Organic carbon (OC), elemental carbon (EC), water-soluble inorganics (WSIs), water-soluble organic acids (WSOAs), water-soluble amine salts (WSAs), trace mineral elements (THMs), polycyclic aromatic hydrocarbons (PAHs), and phenols in smoke $\mathrm{PM}_{1.0} / \mathrm{PM}_{2.5}$ are 1.34-6.04/1.54$7.42, \quad 0.58-2.08 / 0.61-2.18, \quad 0.51-3.52 / 0.52-3.81, \quad 0.13-$ $0.64 / 0.14-0.77, \quad(4.39-85.72 / 4.51-104.79) \times 10^{-3}, \quad(11.8-$ $51.1 / 14.0-131.6) \times 10^{-3}, \quad(1.1-4.0 / 1.8-8.3) \times 10^{-3}, \quad$ and $(7.7-23.5 / 9.7-41.5) \times 10^{-3} \mathrm{~g} \mathrm{~kg}^{-1}, \quad$ respectively. Black carbon (BC) mainly exists in $\mathrm{PM}_{1.0}$; heavy-metal-bearing particles favour residing in the range of smoke $\mathrm{PM}_{1.0-2.5}$, which is also confirmed by individual particle analysis.

With respect to the five scenarios of burning activities, the average emissions and overall propagation of uncertainties at the $95 \%$ confidence interval (CI) of SPM from agricultural open burning in China in 2012 were estimated to be 1005.7 $(-24.6,33.7 \%), 901.4(-24.4,33.5 \%), 432.4(-24.2$, $33.5 \%), 134.2(-24 ., 34.0 \%), 249.8(-25.4,34.9 \%), 25.1$ $(-33.3,41.4 \%), 5.8(-30.1,38.5 \%), 8.7(-26.6,35.6 \%)$,
$0.5(-26.0,34.9 \%)$, and $2.7(-26.1,35.1 \%) \mathrm{Gg}$ for $\mathrm{PM}_{2.5}$, $\mathrm{PM}_{1.0}$, OC, EC, WSI, WSOA, WSA, THM, PAHs, and phenols, respectively. The emissions were further spatiotemporally characterized using a geographic information system (GIS) in different regions in the summer and autumn post-harvest periods. It was found that less than $25 \%$ of the total emissions were released during the summer harvest, which was mainly contributed by the North Plain and the centre of China, especially Henan, Shandong, and Anhui, which are the top three provinces regarding smoke particle emissions.

Flux concentrations of primarily emitted smoke $\mathrm{PM}_{2.5}$ that were calculated using the box-model method based on five versions of emission inventories all exceed the carcinogenicrisk permissible exposure limits (PEL). The health impacts and health-related economic losses from the smoke $\mathrm{PM}_{2.5}$ short-term exposure were assessed. The results show that China suffered from 7836 cases $(95, \%$ CI: 3232, 12362) of premature mortality and 7267237 cases (95\% CI: 2961 487, 1130784 ) of chronic bronchitis in 2012, which led to losses of USD 8822.4 million (95\% CI: 3574.4, 13034.2 ) or $0.1 \%$ of the total GDP. We suggest that the percentage of openburnt crop straw in the post-harvest period should be cut down by over $97 \%$ to ensure a reduction in carcinogenicity risk, especially in the North Plain and the northeast, where the emissions should decrease at least by $94 \%$ to meet the 
PEL. With such emission control, over $92 \%$ of the mortality and morbidity attributed to agricultural fire smoke $\mathrm{PM}_{2.5}$ can be avoided in China.

\section{Introduction}

Biomass burning (BB) is a significant source of particulate and gaseous pollutants (Andreae and Merlet, 2001; Clarke et al., 2007; Ram et al., 2011; Saikawa et al., 2009; Tian et al., 2008). It was estimated that the open burning of biomass contributed approximately $40 \%$ of the globally averaged annual submicron black carbon (BC) aerosol emissions and $65 \%$ of primary organic carbon (OC) emissions (Bond et al., 2013). China is the major contributor with over $24 \%$ of global emissions of carbonaceous aerosols, especially from agricultural field burning; about $0.04-0.5 \mathrm{Tg}$ EC (elemental carbon) and 0.4-2.1 Tg OC are released annually (Bond, 2004; Cao et al., 2006; Qin and Xie, 2012; Saikawa et al., 2009), resulting in great radiative forcing, air quality deterioration, visibility reduction, premature mortality, and economic loss regionally and globally (Bølling et al., 2009; Bond et al., 2013; Huang et al., 2014; Janssen et al., 2011; Rosenfeld, 2006; Saikawa et al., 2009; Shindell et al., 2012).

$\mathrm{BB}$ also represents one of the greatest uncertainties in emission, climate effect, and public health assessments, which ultimately rely on the uncertainties in detailed chemical emissions or related properties and burning activities, such as the strength or percentage of biomass fuel burnt (Tian et al., 2008; Andreae and Merlet, 2001; Levin et al., 2010). For example, studies have focused on OC and EC emissions due to their specific optical properties (Bond et al., 2013; Cao et al., 2006; Qin and Xie, 2012; Ram et al., 2011). OC, like sulfate and nitrate, can cool the atmosphere by increasing the Earth's reflectivity; however, smoke OC on the other hand has been treated as brown carbon, which exhibits a pronounced light absorption character (Chen et al., 2015; Ackerman, 2000; Chakrabarty et al., 2010; Christopher et al., 2000). Coated or internally mixed sulfate or nitrate can act as a lens to enhance the light absorption activity of BC (R. Zhang et al., 2008) and probably also the activity of brown carbon (Chen et al., 2015). However, primary emissions for OC, EC, and alkali components are confused and have a wide range (Sen et al., 2014; Cao et al., 2006; Hayashi et al., 2014), and some studies still considered OC to have negative forcing activity (Saikawa et al., 2009; Shindell et al., 2012). Besides, smoke EC consists of soot and char, and soot EC has a higher light absorption potential compared to char EC (Arora and Jain, 2015; Reid et al., 2005a). The division and quantification of char- and soot-EC emissions for biomass burning are understudied (Arora and Jain, 2015; Han et al., 2007, 2009). Moreover, the values for other components like organic acids, amines, phenols, and mineral elements that enable cloud condensation nucleus activity or carry the health hazard of smoke aerosol are also deficient, variable, or outdated, which may hinder our overall understanding of biomass burning contributions and also of the atmospheric process of smoke particles (Li et al., 2015; Akagi et al., 2011; Chan et al., 2005; Dhammapala et al., 2007a; Ge et al., 2011; Reid et al., 2005a, b).

Studies using carbon mass balance (CMB) and pollutant concentration-chamber volume quantification are two common methods to derive the emission factors for biomass burning aerosols (Akagi et al., 2011; Li et al., 2007; H. Zhang et al., 2008). Carbonaceous and inorganics components of smoke particles not only vary with biomass issues (fuel types, water content, or burning strength) but also relate to burning conditions and environment (flaming or smoldering, field burning or laboratory simulation), the extent of aging, sampling methods, and measurement technologies (Grieshop et al., 2009; Hayashi et al., 2014; Reid et al., 2005b). Compared to field observations that are closer to the actual burning (Li et al., 2007; Akagi et al., 2011; Rose et al., 2011; Saffari et al., 2013), laboratory studies have a definite advantage over field burning research in emission analysis (Jayarathne et al., 2014; Sun et al., 2016; H. Zhang et al., 2008). For example, the environment, amount of fuel, and burning conditions can be precisely controlled, the contamination from ambient atmosphere to the emissions can be excluded, and chemical compositions at different stages of aging can be quantified using an aerosol chamber system (Li et al., 2015, 2016; Aurell et al., 2015; Dhammapala et al., 2007b).

The activity rates of biomass burning (burning rate of biomass fuels) are also a response to the great uncertainties in the emission estimates (Sun et al., 2016; H. Zhang et al., 2008). Studies have rarely focused on the burning rates, and the limited data were treated as a simplex constant or dynamic values in many studies of emission estimation in a certain year or for annual variations with a long timescales; thus, significant differences among the results were founded (Qin and Xie, 2011, 2012; Zhang et al., 2011; Zhao et al., 2012). For instance, Cao et al. (2006, 2011) estimated primary smoke carbonaceous material emissions for 2000 and 2007 in China with same field burning rates; the results were almost the same for the 2 years in which 103$104 \mathrm{Gg} \mathrm{yr}^{-1} \mathrm{BC}$ and $425.9-433.3 \mathrm{Gg} \mathrm{yr}^{-1}$ OC were emitted. He et al. (2011) found declining trends in biomass burning emissions in the Pearl River delta for the period 20032007 based on constant activity data of burning rates. Lu et al. (2011) developed primary carbonaceous aerosol emissions in China for 1996-2010; with time-dependent activity rates extrapolated from 2008 to 2010 based on national fasttrack statistics, rapid increases in OC and EC emissions were reported, and OC increased from 1.5 to $2.3 \mathrm{Tg} \mathrm{yr}^{-1}$ and $\mathrm{BC}$ increased from 418 to $619 \mathrm{Gg} \mathrm{yr}^{-1}$. Qin and Xie (2012) estimated BC emission from crop straw open burning for 19802009 with variable burning rates based on the development of farmers' income. The increasing trend in $\mathrm{BC}$ emission 
was also confirmed, and $\mathrm{BC}$ emission increased from 4.3 to 116.6 $\mathrm{Gg} \mathrm{yr}^{-1}$.

As most anthropogenic pollutants are concentrated in submicron particulate matter $\left(\mathrm{PM}_{1.0}\right)$ (Ripoll et al., 2015), a more pronounced relationship of ambient $\mathrm{PM}_{1.0}$ to haze formation and adverse health effect has been reported (Huang et al., 2003; Roemer and van Wijnen, 2001; Shi et al., 2014). Nevertheless, the associated chemical characterization of $\mathrm{PM}_{1.0}$ is still undefined (Li et al., 2015; Safai et al., 2013; Cheng et al., 2006). The study of source-specific $\mathrm{PM}_{1.0}$ chemical compositions and emissions is necessary to replenish databases for contribution assessment and model application in atmospheric chemistry, climate change, and public health evaluation.

The emission inventories and forecasting of the emission of atmospheric pollutants have been widely studied, and the incurred mortality, climatic effect, and economic loss have also been estimated (Ostro and Chestnut, 1998; Saikawa et al., 2009; Shindell et al., 2012), based on which the emission control policies were proposed. Shindell et al. (2012) considered $\sim 400$ control measures in tropospheric $\mathrm{BC}$ and $\mathrm{O}_{3}$ emissions for the benefit of global or regional human health and food security, and 14 optimal measures targeting $\mathrm{CH}_{4}$ and BC emissions were identified. Saikawa et al. (2009) compared different scenarios of OC, EC, and sulfate emissions in China in 2030, concluding that a maximum feasible reduction may avoid over 480000 premature deaths in China and decrease the radiative force from -97 to $-15 \mathrm{~mW} \mathrm{~m}^{-2}$ globally. L. Wang et al. (2008) reported that field burning restriction may prevent about USD 5 billion losses due to biological resources and air pollution. However, the generalized strategies in emission reduction were inadequate and lack actual practicality (Streets, 2007; Lin et al., 2010).

In this study, burning experiments with five major agricultural straw were conducted using a combustion stove in combination with an aerosol chamber system. Accurate compositions and emission factors for smoke particulate matter (SPM) in $\mathrm{PM}_{1.0}$ and $\mathrm{PM}_{2.5}$ were characterized and established. Afterwards, up-to-date emissions for agricultural open-burning aerosol in 2012 were developed; health and health-related economic impacts from smoke $\mathrm{PM}_{2.5}$ exposure were also assessed. Finally, an emission reduction strategy that was implemented at a field burning rate control regarding the carcinogenic risk was proposed, which should help establish policy and provide an idea for emission control.

\section{Methodology}

An overview of the research procedures including emission factor acquirement and emission inventory calculation is shown in Fig. 1. The tabulation of emission factors is established in our laboratory using a combustion stove to simulate open burning and an aerosol chamber to quantify the emissions. Then, we use a bottom-up approach to calculate the emission inventory of agricultural field burning over the Chinese mainland based on crop production data from 2012. Emissions for each species are estimated as

$E_{k, j}=\sum_{i} A_{k, i} \times \mathrm{EF}_{i, j}$,

where $E_{j}$ is emission, $A_{k, i}$ is effective biofuel consumption, and $\mathrm{EF}_{i, j}$ is the emission factor. $k, i$, and $j$ indicate region, agricultural residue type, and particulate chemical species, respectively.

State-of-the art chemical transport and box models were commonly applied to reproduce or simulate the ambient aerosol concentrations (Ram et al., 2011; Reddy and Venkataraman, 2000; Saikawa et al., 2009). In this study, a spatio-temporal dynamic box model is used to calculate the emission flux concentration. Regional crop straw was assumed to be combusted proportionally only on the fire occurrence days. If one dismisses the interaction of emitted pollutants in space and time, pollutants will distribute uniformly in a space covering an area of a specific region with a mixing height of $0.5 \mathrm{~km}$ (atmospheric boundary layer). The flux concentration of agricultural burning smoke can be calculated by Eq. (2):

$C_{k, j}=\frac{E_{k, j}}{S_{k} \times h \times T_{k}}$,

where $C_{k, j}$ is the flux concentration of smoke aerosol, $S_{k}$ is the regional area, $h$ is the boundary layer height, and the $T_{k}$ is agricultural field fire duration time.

\subsection{Aerosol chamber work and emission factors}

\subsubsection{Crop straw}

Five kinds of representative crop residues were used for the burning experiments, i.e. wheat, rice, corn, cotton, and soybean straw. The straw was collected based on regional features of agricultural planting: winter wheat straw was collected from Anhui province, late rice straw from Shanghai, corn straw from Henan province, and cotton and soybean residues from Xinjiang. All straw was stored in dark, wellaired, and cool conditions. Prior to the burning experiment, dirt and weeds were removed; then straw was dehydrated (at $100{ }^{\circ} \mathrm{C}$ for $24 \mathrm{~h}$ ) to minimize the effect of the water content on the burning and pollutant emissions, as a study found that pollutant emissions and combustion efficiencies (CEs) are a response to water content. Increased moisture content enhances the emissions but also alters the chemical compositions of smoke aerosols (Reid et al., 2005b; Aurell et al., 2015; Hayashi et al., 2014). Although straw in the field is not well dried and moisture contents vary with the weather, ventilation, and storing times, for the convenience of practical application and a comparison of burning and emissions, the water contents of the straw were controlled to within $2 \mathrm{wt} \%$, 


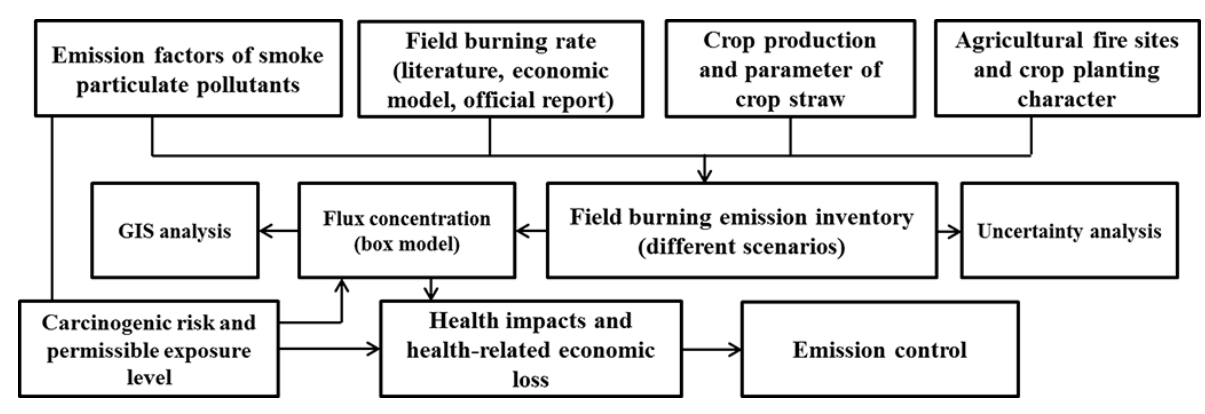

Figure 1. Schematic methodology for developing emission estimations.

which has been applied in many studies (Hayashi et al., 2014; Huo et al., 2016; Li et al., 2015; Oanh et al., 2011; H. Zhang et al., 2008, 2011). The dry straw was then cut to a length of approximately $10 \mathrm{~cm}$ and weighed to $10.0 \mathrm{~g}$ per serving.

\subsubsection{Burning experiments}

The experiments were conducted using an aerosol chamber system (Fig. S1 in the Supplement), which was loaded in a temperature-controlled room $\left(18-22{ }^{\circ} \mathrm{C}, 40-60 \%\right.$ relative humidity, RH). A self-designed stainless combustion stove was used to simulate typical field burning of crop straw by automatic ignition with LPG (liquid petroleum gas) but on a small scale (ignition time less than $0.1 \mathrm{~s}$ ). In total, $10.0 \mathrm{~g}$ conditioned residues were sealed in the $0.227 \mathrm{~m}^{3}$ combustion stove in advance. Once ignited, the force ventilation and HEPA filtrated particle-free air were supplied $\left(300 \mathrm{~L} \mathrm{~min}^{-1}\right)$. The emissions were immediately injected into a clean, evacuated aerosol chamber. The burning lasted about $1 \mathrm{~min}$ and over $1 \mathrm{~m}^{3}$ particle-free air flushed the stove to ensure all the emissions were transferred into the chamber.

The chamber was custom-built to quantify the emissions and characterize the physicochemical properties of smoke aerosols. Detailed description of the chamber can be found elsewhere (H. Zhang et al., 2008, 2011; Li et al., 2015, 2016). Briefly, the chamber has a volume of $4.5 \mathrm{~m}^{3}$ with $0.3 \mathrm{~mm}$ Teflon coating on the inner side, a magnetic fan fixed on the bottom to stir the aerosol uniformly, and a hygroclip monitor (Rotronic, Model IM-4) inside the chamber to measure the temperature and relative humidity of the aerosol. Before the experiment, the chamber was flushed with particle-free air for $6 \mathrm{~h}$, oxidized by high-concentration ozone $(\sim 3 \mathrm{ppm})$ for $12 \mathrm{~h}$, flushed and vacuumized, and filled with pure dry air to $80 \mathrm{KPa}$ for use. The emissions from straw burning were directed into the chamber until it was at room pressure. Afterwards, size measurement and sampling of smoke aerosols were conducted from the chamber. For each type of straw, four burning experiments were conducted. The unburnt residues were weighed and deducted from $10.0 \mathrm{~g}$ after each test.

The modified combustion efficiency (MCE) for each burning was monitored through measuring $\mathrm{CO}$ and $\mathrm{CO}_{2}$ to de- termine the burning phase and to ensure the repeatability. MCE is defined as $\Delta \mathrm{CO}_{2} /\left(\Delta \mathrm{CO}_{2}+\Delta \mathrm{CO}\right)$, where $\Delta \mathrm{CO}_{2}$ and $\Delta \mathrm{CO}$ are the excess molar mixing ratios of $\mathrm{CO}_{2}$ and $\mathrm{CO}$ (Reid et al., 2005b). A gas chromatograph (GC, model 930, Shanghai, Hai Xin Gas Chromatograph Co., Ltd) equipped with a flame ionization detector, an $\mathrm{Ni}-\mathrm{H}$ convertor, and a stainless-steel column ( $2 \mathrm{~m}$ long) packed with $15 \%$ DNP was used to measure $\mathrm{CO}$ and $\mathrm{CO}_{2}$ concentrations in the chamber. MCE was 0.89-0.96 for all the experiments (see Table S1 in the Supplement), indicating that flaming combustion dominated. This was comparable to field burning ( $\mathrm{Li}$ et al., 2003, 2007).

\subsubsection{Size and morphology of smoke aerosol}

The size distribution $(10 \mathrm{~nm}-10 \mu \mathrm{m})$ of smoke particles was measured using a wide-range particle spectrometer (WPS; Model 1000XP, TSI, USA), which has been described by $\mathrm{Li}$ et al. (2015). Briefly, WPS integrates the function of a scan mobility particle sizer (SMPS) and a laser particle sizer (LPS); $0.3 \mathrm{~L} \mathrm{~min}^{-1}$ flow is introduced to the SMPS to classify the mobility size from 10 to $500 \mathrm{~nm}$ in 48 bins, and $0.7 \mathrm{~L} \mathrm{~min}^{-1}$ flow is introduced to the LPS part to measure the aerodynamic diameter from $350 \mathrm{~nm}$ to $10 \mu \mathrm{m}$ in 18 bins. Particle density, refractive index, and scanning time were set as $1.0 \mathrm{~g} \mathrm{~cm}^{-3}, 1.45$, and $3 \mathrm{~min} \mathrm{loop}^{-1}$, respectively, and the charge correction mode was on for the measurement. A diffusion dryer tube $(45 \mathrm{~cm}$ in length) filled with descant-silica gel was set in front of the inlet of WPS. Before the experiment, the WPS was calibrated with certified polystyrene latex spheres (PSLs; 40, 80, and $220 \mathrm{~nm}$, Duke Scientific).

SPM from five types of crop straw burning was sampled onto copper grids coated with carbon film (carbon type-B, 300-mesh copper; Tianld Co., China) using a single-stage cascade impactor with a $0.5 \mathrm{~mm}$ diameter jet nozzle at a flow rate of $1.0 \mathrm{~L} \mathrm{~min}^{-1}$. The sampler has a collection efficiency of $100 \%$ at $0.5 \mu \mathrm{m}$ aerodynamic diameter. More information about the cascade impactor can be found elsewhere (Fu et al., 2012; Hu et al., 2015). Then, a JEOL-2010F field emission high-resolution transmission electron microscope (FEHRTEM) coupled with an Oxford energy-dispersive X-ray 
spectrum (EDX) was applied to investigate the morphology, composition, and mixing state of individual particles.

\subsubsection{Chemical sampling and analysis}

$\mathrm{PM}_{1.0}$ and $\mathrm{PM}_{2.5}$ samples for each burning were collected from the chamber on a pretreated quartz filter of $90 \mathrm{~mm}$ in diameter (Tissuquartz, Pall Corp., USA) using a high-volume particle sampler (HY-100, Qingdao Hengyuan S. T. Development Co., Ltd) operating at $100 \mathrm{~L} \mathrm{~min}^{-1}$. Each filter sampling duration time is $5 \mathrm{~min}$, and a total of 44 samples (including 4 blank samples) were gathered. The quartz microfibre filters were prebaked for $8 \mathrm{~h}$ at $450{ }^{\circ} \mathrm{C}$ to eliminate contamination. Before and after the sampling, the filters were weighed using a balance (Sartorius BP211D) with an accuracy of $10 \mu \mathrm{g}$, and the filters were balanced in an electronic desiccator $\left(40 \% \mathrm{RH}, 22^{\circ} \mathrm{C}\right)$ for $24 \mathrm{~h}$ before usage. After weighing, the loaded filters were stored at $-20^{\circ} \mathrm{C}$ in a refrigerator for further analysis.

Water-soluble species including general inorganic ions $\left(\mathrm{F}^{-}, \mathrm{Cl}^{-}, \mathrm{NO}_{2}^{-}, \mathrm{NO}_{3}^{-}, \mathrm{SO}_{4}^{2-}, \mathrm{Na}^{+}, \mathrm{NH}_{4}^{+}, \mathrm{K}^{+}, \mathrm{Ca}^{2+}\right.$, $\left.\mathrm{Mg}^{2+}\right)$, organic acids $\left(\mathrm{CH}_{3} \mathrm{COOH}, \mathrm{HCOOH}, \mathrm{C}_{2} \mathrm{H}_{2} \mathrm{O}_{4}\right.$, $\left.\mathrm{CH}_{3} \mathrm{SO}_{3} \mathrm{H}\right)$, and seven protonated amines $\left(\mathrm{MeOH}^{+}, \mathrm{TeOH}^{+}\right.$, $\mathrm{MMAH}^{+}, \mathrm{DMAH}^{+}, \mathrm{TMAH}^{+}, \mathrm{MEAH}^{+}$, and $\mathrm{DEAH}^{+}$, corresponding to monoethanolaminium, triethanolaminium, monomethylaminium, dimethylaminium, triethylaminium, monoethylaminium, and diethylaminium) were measured from one quarter of each filter with ion chromatography (IC; Model 850 Professional IC, Metrohm, USA) consisting of a separation column (Metrosep A Supp 7 250/4.0 for anion and organic acids, Metrosep C-4 150/4.0 for cation, and Metrosep C4-250/4.0 for water-soluble aminiums). Sampled filters were ultrasonically extracted with $15.0 \mathrm{~mL}$ deionized water (Mili-Q water, $18.2 \mathrm{M} \Omega \mathrm{cm}^{-1}$ ). Extracted solutions were filtrated using $0.2 \mu \mathrm{m}$ filters before injection into IC for measurement. Detection limits (DLs) for the ions and aminiums were within $0.5-3.5 \mathrm{ng} \mathrm{mL}^{-1}$, the correlation coefficients for all calibration curves were better than 0.99 , and recovery rates for aminiums were in the range of $93-106 \%$ (see Table S2). Details of the aminium measurements can be found in Tao et al. (2016).

One quarter of each filter was acid dissolved to measure the selected elements (As, $\mathrm{Pb}, \mathrm{Cr}, \mathrm{Cd}, \mathrm{Ni}, \mathrm{V}, \mathrm{Zn}, \mathrm{Al}$ ), of which $\mathrm{As}, \mathrm{Zn}, \mathrm{Pb}, \mathrm{Cr}, \mathrm{Cd}$, and Ni are US EPA (Environmental Protection Agency) priority-controlled pollutants (Wu et al., 2011). The smashed filters were digested at $170^{\circ} \mathrm{C}$ for $4 \mathrm{~h}$ in a high-pressure Teflon digestion vessel with $3.0 \mathrm{~mL}$ concentrated $\mathrm{HNO}_{3}, 1.0 \mathrm{~mL}$ concentrated $\mathrm{HClO}_{4}$, and $1.0 \mathrm{~mL}$ concentrated HF. Afterwards, the almost dry solution was diluted and characterized using inductively coupled plasma optical emission spectrometer (ICP-OES; Atom Scan 2000, JarroU-Ash, USA). The following wavelength lines of the ICP-OES analysis were used: As 189.042, $\mathrm{Pb} 220.353$, Cd 228.802, Cr 205552, Ni 231.604, V 311.071, $\mathrm{Zn}$ 206.191, and Al 394.401. All reagents used were of the highest grade, and recovery tests were conducted with standard additions. Recoveries of each element were in the range of $93-102 \%$ (see Table S2).

Another one quarter of each filter was ultrasonically double extracted with $15.0 \mathrm{~mL}$ HPLC-grade $\mathrm{CH}_{2} \mathrm{Cl}_{2}$. The extracts were then condensed with a rotary evaporator and quantified to $1.0 \mathrm{~mL}$. Overall, 16 targeted polycyclic aromatic hydrocarbons (PAHs) (two-ring: naphthalene (Nap); three-ring: acenaphthylene (Ac), acenaphthene (Ace), fluorene $(\mathrm{Fl})$, phenanthrene (Phe), anthracene (Ant); four-ring: fluoranthene (Flu), pyrene (Pyr), benzo[a]anthracene (BaA), chrysene (Chr); five-ring: benzo[b]fluoranthene (BbF), benzo[k]fluoranthene $(\mathrm{BkF})$, benzo[a]pyrene $(\mathrm{BaP})$, dibenzo[a,h]anthracene (DBA); and six-ring: indeno[1,2,3cd] pyrene (IP), benzo[ghi]perylene (BghiP)) and five selected phenols (phenol, 2-methoxyphenol, 4-ethylphenol, 4-ethyl-2-methoxyphenol, 2,6-dimethoxyphenol) were measured from the concentrated extracts using an Agilent 6890 Series gas chromatography system coupled with a HP 5973 mass selective detector (GC-MS, Agilent Technologies, Wilmington, DE). A DB- $5 \mathrm{~ms}(30 \mathrm{~m} \times 0.32 \mathrm{~mm} \times 0.25 \mathrm{~mm}$, Agilent 123-5532) column was installed. The temperature programs were presented as follows: start at $40^{\circ} \mathrm{C}$; hold for $4 \mathrm{~min}$, to $150^{\circ} \mathrm{C}$ at $20^{\circ} \mathrm{Cmin}^{-1}$, then to $280^{\circ} \mathrm{C}$ at $5^{\circ} \mathrm{C} \mathrm{min}^{-1}$; hold for $10 \mathrm{~min}$. The interface temperature was kept at $280^{\circ} \mathrm{C}$. The MS (mass spectrometer) was operated in electron impact mode with an ion source temperature of $230^{\circ} \mathrm{C}$, and the high-purity helium $(99.999 \%)$ carrier gas was maintained at a constant pressure of 16.2 psi with a flow of $2.0 \mathrm{~mL} \mathrm{~min}^{-1}$. The calibration curves were optimized to be better than $99.9 \%$. Prior to the measurements, PAH and phenol recovery studies were undertaken, and recoveries were acceptable, with rates of $82-99 \%$ (see Table S2). In addition, phenanthrene-d10 (Phe-d10), as an internal standard surrogate was added into the PAH mixture, the recovery rate of which was $94 \%$.

OC and elemental carbon (EC) were measured with the remaining quartz filters using a carbon analyser (Sunset laboratory Inc., Forest Grove, OR) based on the thermaloptical transmittance (TOT) method with a modified NIOSH5040 (National Institute of Occupational Safety and Health) protocol. Four organic fractions $(\mathrm{OC} 1, \mathrm{OC} 2, \mathrm{OC} 3$, and $\mathrm{OC} 4$ at $150,250,450$, and $550^{\circ} \mathrm{C}$, respectively), PC fraction (a pyrolyse carbonaceous component determined when transmitted laser returned to its original intensity after the sample was exposed to oxygen), and three EC fractions $\left(\mathrm{EC} 1, \mathrm{EC} 2\right.$, and $\mathrm{EC} 3$ at 550,700 , and $800^{\circ} \mathrm{C}$, respectively) were produced. OC is technically defined as $\mathrm{OC} 1+\mathrm{OC} 2+\mathrm{OC} 3+\mathrm{OC} 4+\mathrm{PC}$, while $\mathrm{EC}$ is defined as $\mathrm{EC} 1+\mathrm{EC} 2+\mathrm{EC} 3-\mathrm{PC}$ (Seinfeld and Pandis, 2012). The instrument detection limits for total $\mathrm{OC}$ and $\mathrm{EC}$ that deposit on the filter are 0.25 and $0.12 \mu \mathrm{g} \mathrm{cm}^{-2}$. The quality of the data above was guaranteed by standard material calibration, recovery rate, and operational blank correction. Blank levels were less than $5 \%$ of the measured values for all the species. 


\subsubsection{Calculation of emission factors}

The emission quantities derived from the experiment were converted into quantities per unit weight of initial residues as emission factor (EF; unit: $\mathrm{g} \mathrm{kg}^{-1}$ ), which can be calculated from the direct method with the effective filter sampling weight, chamber volume, and the effective amount of crop straw consumed (Dhammapala et al., 2006, 2007a, b; H. Zhang et al., 2008), or alternatively from the carbon mass balance (CMB) method via the conservation of carbon in biomass, disregarding the weight of biomass that burnt (Dhammapala et al., 2006; Li et al., 2007). EFs determined from these two methods were found to be in good agreement (Dhammapala et al., 2006); nevertheless, the CMB method needs more auxiliary information (e.g. concentrations of $\mathrm{CO}$, $\mathrm{CO}_{2}, \mathrm{CH}_{4}$, non-methane hydrocarbons, and also particulate carbons), which may result in data redundancy and uncertainty propagation. Hence, we applied the direct method to calculate EFs in this work. To be more accurate, the influence of wall loss and dilution due to the makeup of the air supply on smoke particles sampling from the chamber were considered and corrected; for details, see the Supplement.

In this study, the duration of each test (burning, chamber condition, size measurement, and filter sampling) was set to within $20 \mathrm{~min}$. Therefore, the physicochemical processes of pollutants in the chamber can be negligible, and the smoke aerosols we measured were primary emissions.

\subsection{Emission inventory calculation}

\subsubsection{Agricultural field fire survey}

Fire sites over China from 2011 to 2013 were statistically analysed, and the data of mainland agricultural fire sites was derived from the daily report of the Ministry of Environmental Protection of China (MEPC) (website: http://hjj.mep.gov. $\mathrm{cn} / \mathrm{jgjs} /$ ). Agricultural fire sites were selected from MODIS (Moderate Resolution Imaging Spectroradiometer) daily fire products $(1 \mathrm{~km} \times 1 \mathrm{~km}$ resolution, level 3 hotspot $)$ using a high-resolution real-time land use based on the geography information system (GIS). Spatial and temporal distributions of fire sites are displayed in Fig. S2. Over 5000 fire sites were allocated to two prominent burning periods corresponding to summer (May to July) and autumn (September to November) harvests, and the field burning lasted 54 and 60 days on average during the two harvests. In the north of China, open burning occurred primarily in autumn, while the temporal character of field fires was not obvious in the North Plain and the centre of China, where field fires can be observed frequently during the whole investigation time.

\subsubsection{Crop straw production}

Crop straw production was generally derived from annual or monthly crop production by multiplying crop-specific ratios of residue to production (He et al., 2011; Cao et al., 2011;
Zhao et al., 2012). In this study, crop production was further classified as summer harvest and autumn harvest production according to field fire sites analysis and traditional seasonal planting and harvesting. The amount of straw produced was calculated by Eq. (3):

$M_{t, k, i}=P_{t, k, i} \times r_{i} \times H_{t, k, i} \times D_{i}$,

in which $M$ is the mass of crop straw produced, $P$ is the annual crop-specific amount of crop production, $r$ is the residue-to-production ratio, $D$ is the dry matter content, and $H_{t, k, i}$ is the production ratio of crop $i$ in the region $k$ during the summer or autumn harvest period $t$.

Province-level crop production data of wheat, rice, corn, cotton, and soybean were taken directly from the China Yearbook 2013 (NBSC, 2013). Crop-specific residue-toproduction ratios were cited from the Chinese Association of Rural Energy Industry (Wang and Zhang, 2008; data available at http://www.carei.org.cn/index.php, in Chinese). Dry matter contents of crop straw were taken from He et al. (2011) and the Greenhouse Gas Inventory Reference Manual (IPCC, 2007). The parameters of residue-toproduction ratios and dry matter contents were summarized in Table S3. The regional crop production ratios in summer and autumn harvests were listed in Table S4.

\subsubsection{Field burning rate}

The uncertainty of emission estimations mostly relies on the fluctuating nature of the straw open-burning rate (Zhao et al., 2012; He et al., 2011). However, the regional or national percentage of open-burnt straw has seldom been studied, and the limited data are outdated and variable. The available studies indicate that the national field burning rate of crop straw ranges from 15.2 to $27.2 \%$ in China (Daize, 2000; Wei et al., 2004; H. Zhang et al., 2008), and more detailed studies indicate a rate of about $31.9 \%$ for the crop straw burnt in the Pearl River delta from 2003 to 2007 (He et al., 2011), while the corresponding figures were almost $100 \%$ for the Huabei region in 2003 (Zhao et al., 2012). Two versions of province-level field burning rates are commonly used. One was from Cao et al. $(2005,2006,2011)$, who deduced the rates based on regional economic level, and the proposal that the rates should be proportional to farmers' income was confirmed later. The rates were first used to calculate openburning emission in 2000. The other version was reported by Wang and Zhang (2008), they obtained a provincial percentage of open-burnt residue via a field survey in 2006. Herein, the two versions were both applied directly into the emission estimation for 2012 and referred to as business-as-usual scenarios (BAU, BAU-I from Cao et al., 2005 and BAU-II from Wang and Zhang, 2008).

In fact, the burning rates should be dynamic parameters that are influenced by industrial structure, government policy orientation, and public awareness. With a crop yield increase and energy consumption structure changes in ru- 
ral areas, more straw will be discarded and burnt in the field. Nonetheless, rigorous agricultural fire policy may still prevent the condition from worsening as was possible during 2008 for the Beijing Olympics and 2010 for the Shanghai Expo (Huang et al., 2013; Cermak and Knutti, 2009; Wang et al., 2010). Qin and Xie $(2011,2012)$ deduced year-specific open-burning rates in different zones for the period of 19802009 according to their respective farmer income changes in a certain year on the basis of farmer income and burning rates in 2006. However, the simple linear relationship should be questioned, as a great increase in per capita income after 2006 will surely overestimate the burning rates. We supposed that the burning rates were inversely proportional to farmers' agricultural income proportion (AIP), without considering the policy or potential gain or loss related to agricultural residue treatment. Thus, the burning rates established in 2000 and 2006 from Cao et al. (2005) and Wang and Zhang (2008) can be converted into that of 2012 based on economic data from the equation below:

$R_{k, 2012}=\frac{I_{k, 2012}}{\mathrm{AI}_{k, 2012}} \times \frac{\mathrm{AI}_{k, y}}{I_{k, y}} \times R_{k, y}$,

where $R$ is the agricultural straw field burnt rate, $I_{k, y}$ is farmers' annual income, and $\mathrm{AI}_{k, y}$ is farmers' annual agricultural income. $y$ indicates the reference year (2000 for BAU-I, and 2006 for BAU-II). $I_{k, y}$ and $\mathrm{AI}_{k, y}$ can be found or calculated from the China Yearbook and China Rural Statistic Yearbook (NBSC, 2004-2013).

The versions of converted rates based on the primary industry level were called Economic Models I and II (EM-I and EM-II for short) corresponding to BAU-I and BAU-II. Besides, in 2013, the National Development and Reform Commission of China published the Chinese agricultural straw treatment report of 2012 (NDRC, 2014, No. 516; data available at http://www.sdpc.gov.cn/, in Chinese) for the first time. The percentages of discarded crop residues in the report were applied in our estimation, which was called the NDRC version.

\subsubsection{Emission and flux concentration}

From the above study, the emission of SPM pollutants can be calculated by reformulating Eq. (1) to get Eq. (5) as is shown below:

$E_{t, k, j}=\sum_{i} M_{t, k, i} \times R_{k} \times f_{i} \times \mathrm{EF}_{i, j}$,

where $E_{t, k, j}$ is the emission amount of chemical species $j$ in region $k$ during the harvest period $t ; f_{i}$ is the burning efficiency; the crop-specific values were cited as 0.68 for soybean residue and 0.93 for the remaining four types of straw (Zhang et al., 2011; Wang and Zhang, 2008; H. Zhang et al., 2008; Koopmans and Koppejan, 1997). Thus, the flux concentration of corresponding pollutants can be also assessed from the box model as mentioned above.

\subsection{Estimate health impacts and health-related economic losses}

\subsubsection{Carcinogenic risk through smoke particulate matter (CRSPM)}

Apart from the enormous climatic effects of smoke particle emissions, new epidemiological and toxicological evidence has also linked carbonaceous aerosol to cardiovascular and respiratory health effects according to the World Health Organization (Bruce et al., 1987; IPCC, 2007). Here, we present the fuel-specific carcinogenic risk of SPM (CRSPM; unit: per $\mu \mathrm{g} \mathrm{m}^{-3}$ ) to assess the health hazard from agricultural straw burning particles and to help source-specific air quality control. The cancer risk attributed to the inhalation of smoke $\mathrm{PM}_{2.5}$ from crop straw $i$ burning was calculated as

$\mathrm{CR}_{i}=\sum_{j} f_{j} \times$ UnitRisk $_{j}$,

where $f_{j}$ is the mass fraction of the individual species $j$ in smoke $\mathrm{PM}_{2.5}$; UnitRisk $j$ is the corresponding unit carcinogenic-risk value of species $j$ extracted from the database provided by the Integrated Risk Information System (IRIS), California Environmental Protection Agency (CEPA), and related documents (Bruce et al., 1987; Burkart et al., 2013; Tsai et al., 2001; Wu et al., 2009, 2011).

$\mathrm{CR}_{i}$ is estimated based on the dose addition model of selected hazardous air pollutants (HAPs) including US EPA priority pollutants of PAHs and heavy metals. UnitRisk values of the selected HAPs are presented in Table S5. Synergistic interactions among pollutants are dismissed, although they are possible. The cancer risk of chromium is adjusted by multiplying by a factor of 0.2 , assuming that only $20 \% \mathrm{Cr}$ measured is in the toxic hexavalent form (Bell and Hipfner, 1997). Benzo[a]pyrene (BaP) is used as an indicator compound of carcinogenicity. The legal threshold of $\mathrm{BaP}$ in most countries ranges from 0.7 to $1.3 \mathrm{ng} \mathrm{m}^{-3}$; the corresponding carcinogenic risk of $\mathrm{BaP}$ is about $1.1 \times 10^{-6}$ per $\mathrm{ng} \mathrm{m}^{-3}$ (Bruce et al., 1987; Burkart et al., 2013). Thus, a carcinogenic potential of one in a million is frequently used to identify the risks of concern in public health and environmental decision making, and the permissible exposure limits (PELs; unit: $\mu \mathrm{g} \mathrm{m}^{-3}$ ) of crop straw burning particles can be estimated as

$\mathrm{PEL}_{i}=\frac{10^{-6}}{\mathrm{CR}_{i}}$.

\subsubsection{Human exposure and health impacts}

A robust relationship between surface $\mathrm{PM}_{2.5}$ and health effects has been revealed and confirmed by many studies (Pope et al., 2004; Wong et al., 2008). PM$_{2.5}$-related health endpoints are composed of a range of elements from sub-clinical effects to the onset of diseases and ultimately death (Davidson et al., 2005). In this study, the incidence of commonly 
studied endpoints, like premature mortality, respiratory and cardiovascular hospital admissions, and chronic bronchitis from primary emitted smoke $\mathrm{PM}_{2.5}$ short-term exposure, were assessed using the Poisson regression model, as shown below (Guttikunda and Kopakka, 2014):

$\Delta E=\Delta \mathrm{Pop} \times \mathrm{IR} \times\left(1-\frac{1}{e^{\beta \times \Delta C}}\right)$,

where $\Delta E$ represents the number of estimated cases of mortality and morbidity, $\Delta C$ is the incremental concentration of particulate matter (PM) or flux concentration, $\Delta \mathrm{Pop}$ is the population exposed to the incremental particulate concentration of $\Delta C$, IR is short for incidence rate of the mortality and morbidity endpoints, and $\beta$ is the coefficient of exposureresponse function, defined as the change in the number of cases per unit change in concentration per capita.

The concentration-response function and incidence rate of each health endpoint are important in health impact evaluation, and they vary for different populations and regions (Yang et al., 2012; Wong et al., 2008). Here, the variance for sex and ages was neglected. Region-specific exposureresponse coefficients for individual mortality were summarized from previous studies, as presented in Table S6. The coefficients for respiratory and cardiovascular hospital admissions and chronic bronchitis were cited as 1.2, 0.7, and $4.4 \%$ (per $10 \mu \mathrm{g} \mathrm{m}^{-3}, 95 \%$ confidence interval, $\mathrm{CI}$ ) from $\mathrm{Au}-$ nan and Pan's work (Aunan and Pan, 2004). This is the case because studies have rarely confirmed these issues in China. Region-specific mortality and hospitalization IRs were taken from statistical reports authorized by the National Health and Family Planning Commission of the People's Republic of China (NHFPC, 2013), and the morbidity due to chronic bronchitis was defined as $13.8 \%$ obased on the fourth national health survey, which was released by the Chinese Ministry of Health in 2008 (CMH, 2009).

\subsubsection{Economic valuation of the health impacts}

The economic losses due to the health impacts associated with smoke $\mathrm{PM}_{2.5}$ exposure in 2012 were further evaluated. The amended human capital (AHC) approach was employed to calculate the unit economic cost of premature mortality. The commonly applied AHC method uses per capita GDP to measure the value of a statistical year of life (IBRD and SEPA, 2007) based on Eq. (9). It can be used as a social statement of the value of avoiding premature mortality and estimates human capital (HC) from the perspective of the entire society, neglecting individual differences (Hou et al., 2012).

$\mathrm{HC}_{k}=\frac{\mathrm{GDP}_{k}}{\mathrm{POP}_{k}} \times \sum_{i=1}^{\tau} \frac{(1+\alpha)^{i}}{(1+\gamma)^{i}}$

$\mathrm{GDP}_{k}$ and $\mathrm{POP}_{k}$ are gross domestic production and population of target region $k$ that were reported in the statistical yearbook in 2012; $\alpha$ and $\gamma$ are economic parameters referring to national GDP growth rate and social discount rate, which were 7.7 and $8.0 \%$ in 2012 from the National Bureau of Statistics of China (NBSC, 2013; data available at http://www.stats.gov.cn/tjsj/ndsj/, in Chinese). $\tau$ is the lifeexpectancy lost due to aerosol pollution, and 18 years of life was widely applied (Hou et al., 2012). The annual exchange rate of USD to CNY was 6.31 in 2012. One can deduce the $\mathrm{HC}$ values of the provinces, municipalities, and autonomous regions in the country, and the calculated regional $\mathrm{HC}$ values are listed in Table S7. In this paper, the cost of respiratory and cardiovascular hospital admissions and chronic bronchitis were USD 632.2, 1223.4, and 948.6 per case in 2012, which were derived from the national health statistical reports (NHFPC, 2013).

The regional and national health-related economic loss from smoke $\mathrm{PM}_{2.5}$ exposure can be calculated based on the excess mortality and morbidity multiplied by the corresponding unit economic values.

\section{Result}

\subsection{Particulate chemical compositions and emission factors}

\subsubsection{Organic carbon and elemental carbon}

An overview of particulate chemical compositions for smoke $\mathrm{PM}_{2.5}$ and $\mathrm{PM}_{1.0}$ is given as pie charts in Fig. 2, and the corresponding emission factors are given in Tables 1 and 2 (detailed EFs for elements, PAHs, and phenols in Table S8 and S9). From multivariate statistical analysis $(P<0.05$ at $95 \% \mathrm{CI}$ ), significant differences in chemical compositions and emissions in size range and fuel types can be observed, implying the non-uniform mixing and distribution of particulate pollutants from biomass burning, which is consistent with the conclusions by Lee et al. (2016) and Giordano et al. (2015). EFs of particulate species from this study were compared with that from the literature as summarized in Table 3. Since EFs in smoke $\mathrm{PM}_{1.0}$ were seldom reported, only smoke $\mathrm{PM}_{2.5}$ or total particulate matter emissions were collected, which were comparable with the results in this work. EFs of smoke $\mathrm{PM}_{2.5}$ and $\mathrm{PM}_{1.0}$ were in the range of 3.2515.16 and $3.04-13.20 \mathrm{~g} \mathrm{~kg}^{-1}$ for the five kinds of crop straw. A high ratio of $\mathrm{PM}_{1.0} / \mathrm{PM}_{2.5}$ was observed: over $90 \mathrm{wt} \%$. This was in line with the size distribution analysis of smoke particles given in Fig. S3. Li et al. (2007) measured the emissions from the field burning of crop straw via the CMB method. $\mathrm{PM}_{2.5} \mathrm{EFs}$ for wheat and corn straw were estimated to be $7.6 \pm 4.1$ and $11.7 \pm 1.0 \mathrm{~g} \mathrm{~kg}^{-1}$ (dry basis, MCE > 0.9), which was higher and presented more uncertainties than our result. As studies have found a positive relationship between particulate EFs and moisture content of agricultural residue (Hayashi et al., 2014), it was reasonable that the combustion of the dehydrated crop straw produced less smoke aerosol in this work. Hayashi et al. (2014) measured particulate EFs 

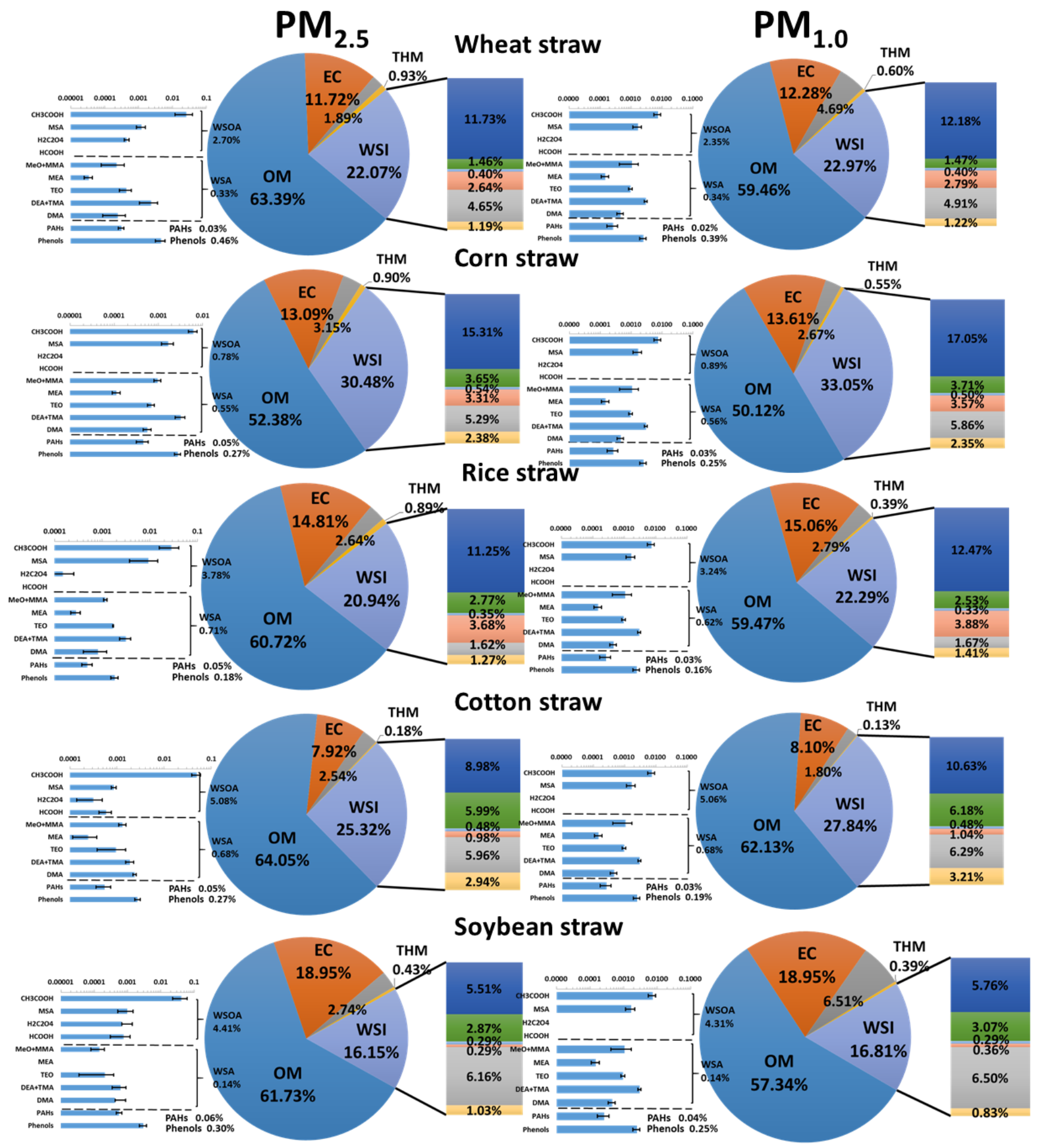

OM $\square \mathrm{EC} \square$ None $\square \mathrm{THM} \square \mathrm{Cl}-\square \mathrm{SO} 42-\square$ NO3- $\square \mathrm{NH} 4+\square \mathrm{K}+\square \mathrm{OWSI}$

Figure 2. Chemical profiles of smoke $\mathrm{PM}_{2.5}$ and $\mathrm{PM}_{1.0}$ from five types of agricultural residue burning. OM (organic matter) is $1.3 \times \mathrm{OC}$. OWSI: other water-soluble ions, including $\mathrm{F}^{-}, \mathrm{NO}_{2}^{-}, \mathrm{Na}^{+}, \mathrm{Ca}^{2+}, \mathrm{Mg}^{2+}$. 
Table 1. Emission factors of particulate chemical species in smoke $\mathrm{PM}_{2.5}$ from agricultural residue burning (mean value $\pm \mathrm{SD}$ ).

\begin{tabular}{|c|c|c|c|c|c|}
\hline Chemical species $\left(\mathrm{g} \mathrm{kg}^{-1}\right)$ & Wheat straw & Corn straw & Rice straw & Cotton residue & Soybean residue \\
\hline $\mathrm{OC}$ & $2.813 \pm 0.147$ & $2.393 \pm 0.351$ & $6.882 \pm 0.689$ & $7.415 \pm 0.547$ & $1.539 \pm 0.253$ \\
\hline Inorganic ions $\left(\mathrm{g} \mathrm{kg}^{-1}\right)$ & $1.273 \pm 0.072$ & $1.810 \pm 0.030$ & $3.086 \pm 0.266$ & $3.810 \pm 0.246$ & $0.523 \pm 0.149$ \\
\hline $\mathrm{SO}_{4}^{2-}$ & $0.084 \pm 0.028$ & $0.217 \pm 0.041$ & $0.409 \pm 0.127$ & $0.701 \pm 0.081$ & $0.073 \pm 0.014$ \\
\hline $\mathrm{F}^{-}$ & $0.023 \pm 0.061$ & $0.061 \pm 0.005$ & $0.073 \pm 0.024$ & $0.265 \pm 0.012$ & $0.009 \pm 0.004$ \\
\hline $\mathrm{NO}_{3}^{-}$ & $0.023 \pm 0.000$ & $0.032 \pm 0.002$ & $0.051 \pm 0.025$ & $0.072 \pm 0.004$ & $0.009 \pm 0.004$ \\
\hline $\mathrm{NO}_{2}^{-}$ & $0.006 \pm 0.001$ & $0.016 \pm 0.002$ & $0.018 \pm 0.002$ & $0.036 \pm 0.001$ & $0.004 \pm 0.003$ \\
\hline $\mathrm{Ca}^{2+}$ & $0.030 \pm 0.011$ & $0.036 \pm 0.003$ & $0.046 \pm 0.007$ & $0.060 \pm 0.003$ & $0.010 \pm 0.002$ \\
\hline $\mathrm{Na}^{+}$ & $0.005 \pm 0.001$ & $0.012 \pm 0.001$ & $0.028 \pm 0.004$ & $0.050 \pm 0.004$ & $0.005 \pm 0.001$ \\
\hline $\mathrm{NH}_{4}^{+}$ & $0.152 \pm 0.005$ & $0.197 \pm 0.010$ & $0.542 \pm 0.107$ & $0.347 \pm 0.008$ & $0.029 \pm 0.004$ \\
\hline $\mathrm{CH}_{3} \mathrm{COOH}$ & $148.900 \pm 79.290$ & $36.640 \pm 8.210$ & $417.930 \pm 186.140$ & $743.320 \pm 159.600$ & $135.500 \pm 62.320$ \\
\hline MSA & $7.170 \pm 2.110$ & $10.030 \pm 30.000$ & $136.990 \pm 81.700$ & $12.980 \pm 1.530$ & $3.200 \pm 1.530$ \\
\hline $\mathrm{H}_{2} \mathrm{C}_{2} \mathrm{O}_{4}$ & $2.610 \pm 0.430$ & ND & $2.210 \pm 1.560$ & $4.760 \pm 2.640$ & $2.170 \pm 2.380$ \\
\hline $\mathrm{HCOOH}$ & ND & ND & ND & $8.930 \pm 2.630$ & $2.440 \pm 1.450$ \\
\hline Amine salts $\left(\mathrm{mg} \mathrm{kg}^{-1}\right)$ & $19.246 \pm 9.368$ & $32.877 \pm 19.141$ & $104.787 \pm 15.635$ & $102.409 \pm 13.379$ & $4.514 \pm 1.776$ \\
\hline $\mathrm{MeOH}^{+}+\mathrm{MMAH}^{+}$ & $1.322 \pm 0.086$ & $5.735 \pm 0.102$ & $17.226 \pm 1.454$ & $19.888 \pm 0.351$ & $0.456 \pm 0.196$ \\
\hline $\mathrm{MEAH}^{+}$ & $0.201 \pm 0.055$ & $0.675 \pm 0.135$ & $4.175 \pm 0.920$ & $3.690 \pm 1.959$ & ND \\
\hline $\mathrm{TEOH}^{+}$ & $2.562 \pm 0.962$ & $4.118 \pm 0.741$ & $25.129 \pm 0.343$ & $14.376 \pm 8.688$ & $0.672 \pm 0.558$ \\
\hline $\mathrm{DEAH}^{+}+\mathrm{TMAH}^{+}$ & $13.728 \pm 7.512$ & $18.973 \pm 0.466$ & $46.148 \pm 12.185$ & $28.568 \pm 5.321$ & $2.012 \pm 0.878$ \\
\hline
\end{tabular}

ND means not detected.

to be 2.2 and $15.0 \mathrm{~g} \mathrm{~kg}^{-1}$ for rice and wheat straw with $\sim 10 \mathrm{wt} \%$ moisture content, while the corresponding EFs increased to 9.1 and $19.5 \mathrm{~g} \mathrm{~kg}^{-1}$ when the water content of straw was $\sim 20 \mathrm{wt} \%$, and linear equations between smoke EFs and straw moisture content were further proposed. However, the simple linearity and its application scope should be questioned, as Hayashi et al. (2014) only considered two water content levels (10 wt \% vs. $20 \mathrm{wt} \%$ ) and disregarded the influence of combustion efficiency for the fires. $\mathrm{PM}_{2.5}$ EFs given by Dhammapala et al. (2006, 2007a, b) were $4.7 \pm 0.4 \mathrm{~g} \mathrm{~kg}^{-1}$ for wheat straw and $12.1 \pm 1.4 \mathrm{~g} \mathrm{~kg}^{-1}$ for herbaceous fuel; these were burnt using a chamber in the flaming phase. A negative response for particulate EFs to combustion efficiency was observed. After all, smoke EFs vary with fires depending on fuel type and moisture, combustion phase, environmental conditions, and some other variables (Reid et al., 2005b).
The carbonaceous materials (organic matter - OM - and EC) dominate in SPM, accounting for about $73.4 \mathrm{wt} \%$ for $\mathrm{PM}_{2.5}$ and $71.3 \mathrm{wt} \%$ for $\mathrm{PM}_{1.0}$ on average. OM was converted from $\mathrm{OC}$ by multiplying by a factor of 1.3 to account for noncarbon materials like oxygen, hydrogen, and other minor species (Li et al., 2007, 2015), and Li et al. (2016) measured the $\mathrm{OM} / \mathrm{OC}$ ratio as $\sim 1.3$ for fresh smoke particles via volatility analysis. EFs of EC and OC from this work were consistent with most studies. Average OC EFs were 4.21 and $3.58 \mathrm{~g} \mathrm{~kg}^{-1}$ in smoke $\mathrm{PM}_{2.5}$ and $\mathrm{PM}_{1.0}$, and the corresponding EC EFs were 1.09 and $1.01 \mathrm{~g} \mathrm{~kg}^{-1}$, respectively. These values fell within the ranges $\left(0.9-9.3 \mathrm{~g} \mathrm{~kg}^{-1}\right.$ for OC and $0.2-1.7 \mathrm{~g} \mathrm{~kg}^{-1}$ for EC) found in other similar sources (Dhammapala et al., 2007a, b; Hayashi et al., 2014; Li et al., 2007; May et al., 2014). Due to the technical limitation and ambiguous artificial boundary, the carbon contents of biomass burning particles have great variability and uncertainty (Lavanchy et al., 1999; Levin et al., 2010). It 
Table 2. Emission factors of particulate chemical species in smoke $\mathrm{PM}_{1.0}$ from agricultural residue burning (mean value \pm SD).

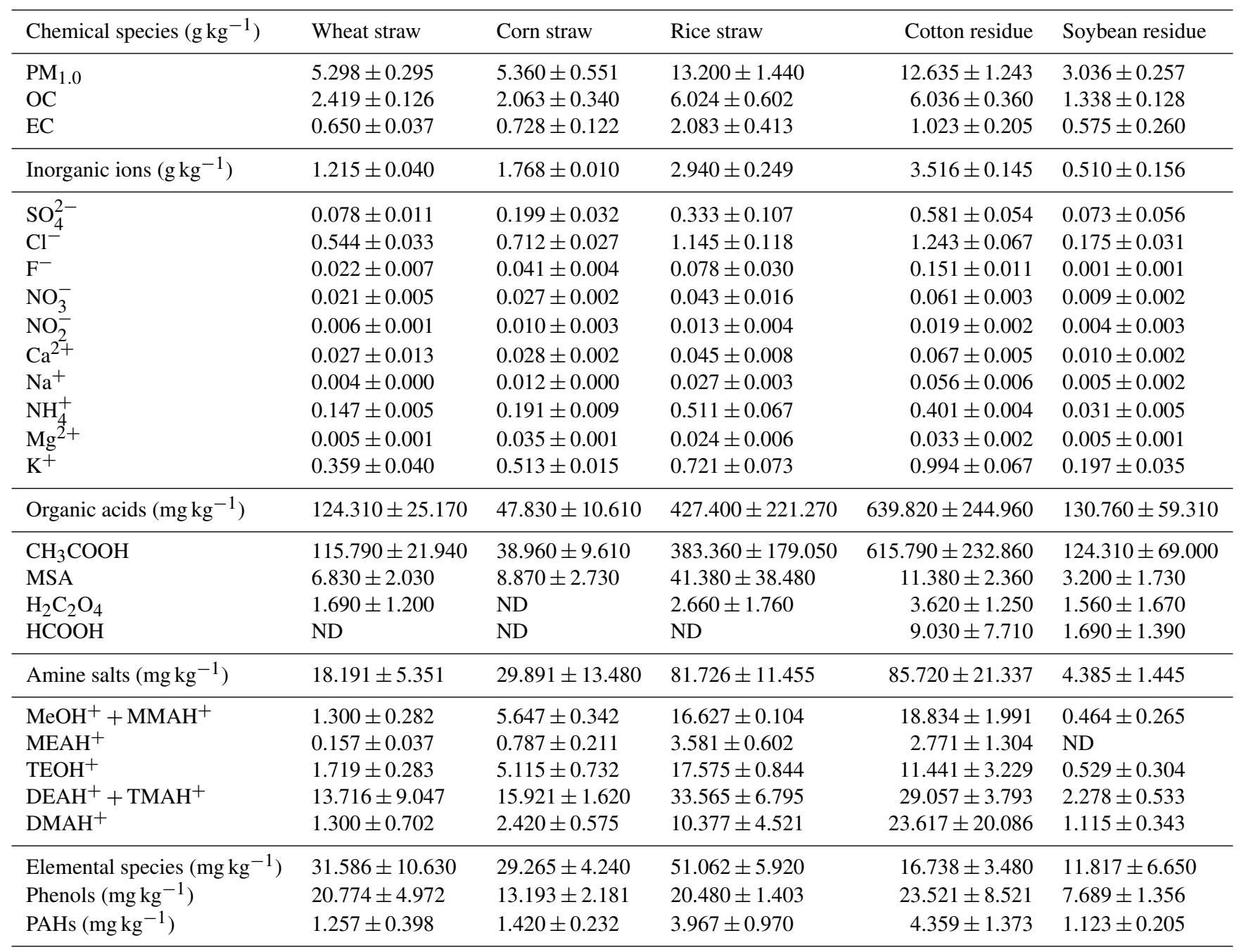

ND means not detected.

was reported that chamber burn studies may overestimate EC EFs due to a misassigned OC-EC split for the heavily massloaded filter samples (Dhammapala et al., 2007b). Moreover, carbon measurement based on the TOT method with the NIOSH protocol may overestimate the OC fraction by sacrificing the EC part compared with the TOR (thermal-optical reflectance) method with the IMPROVE (Interagency Monitoring of PROtected Visual Environments) program (Han et al., 2016). The mass ratio of $\mathrm{OC} / \mathrm{EC}$ is a practical parameter to indicate the primary organic aerosol (OA) emission and secondary organic aerosol (SOA) production. The ratio is influenced by burning conditions, source, aging extent, and particle size (Engelhart et al., 2012; Grieshop et al., 2009). Smoke emitted from smoldering fires is OCdominated, while flaming combustion produces more EC, and the discrepancy of OC / EC ratio can be 1 order of magnitude regarding different combustion phases (Grieshop et al., 2009). SOA production upon photo-oxidation will en- large the OC / EC ratio, and a positive relationship between the oxidation level of $\mathrm{OA}$ loading and the $\mathrm{OC} / \mathrm{EC}$ ratio was reported (Grieshop et al., 2009). Here, the OC / EC ratio in primary emissions varied from 2.4 to 6.2 in the flaming phase, similar to previous studies (Arora and Jain, 2015; Dhammapala et al., 2007a, b; Hayashi et al., 2014; Lewis et al., 2009). The OC / EC ratio was larger in $\mathrm{PM}_{2.5}$, with an average value of 3.8 , while it was 3.6 in $\mathrm{PM}_{1.0}$, indicating that more $\mathrm{EC}$ resides in $\mathrm{PM}_{1.0}$.

\subsubsection{Water-soluble organic acids}

Smoke particles comprise a considerable amount of watersoluble organic acids (WSOAs). This was $3.35 \mathrm{wt} \%$ in $\mathrm{PM}_{2.5}$ and $3.17 \mathrm{wt} \%$ in $\mathrm{PM}_{1.0}$ on average, which is in line with previous work according to which the organic acids measured represent less than $5 \mathrm{wt} \%$ of the total smoke aerosol mass load and tend to partition in a larger size (Falkovich et al., 
Table 3. Comparison of emission factors with the literature (specific chemical materials in the form of $\mathrm{PM}_{2.5}$ ).

\begin{tabular}{llll}
\hline \multirow{2}{*}{ Species } & \multicolumn{1}{c}{ Emission factors $\left(\mathrm{g} \mathrm{kg}^{-1}\right)$} & \multirow{2}{*}{ Reference } \\
\cline { 2 - 3 } & This work & Reference value & \\
\hline $\mathrm{PM}_{2.5}$ & $8.99 \pm 5.55$ & $\begin{array}{l}7.6-11.7(\mathrm{AR}), 6.26-15.3(\mathrm{TL}),-3.0(\mathrm{AR}), \\
2.2-15.0(\mathrm{AR})\end{array}$ & $\begin{array}{l}\text { Li et al. (2007), Akagi et al. (2011), Dhammapala et } \\
\text { al. (2007a), Hayashi et al. (2014) }\end{array}$ \\
\hline $\mathrm{PM}_{1.0}$ & $7.91 \pm 4.67$ & $4.4 .3-12.1(\mathrm{TL})$ & May et al. (2014) \\
\hline OC & $4.21 \pm 2.73$ & $\begin{array}{l}2.7-3.9(\mathrm{AR}), 2.3-9.7(\mathrm{TL}),-1.9(\mathrm{AR}), 1.0-9.3 \text { (AR), } \\
0.8-5.9(\mathrm{TL})\end{array}$ & $\begin{array}{l}\text { Li et al. (2007), Akagi et al. (2011), Dhammapala et } \\
\text { al. (2007a), Hayashi et al. (2014), May et al. (2014) }\end{array}$ \\
\hline EC & $1.09 \pm 0.65$ & $0.35-0.49(\mathrm{AR}), 0.37-0.91(\mathrm{TL}),-0.4(\mathrm{AR})$, & $\begin{array}{l}\text { Li et al. (2007), Akagi et al. (2011), Dhammapala et } \\
\text { al. (2007), Hayashi et al. (2014), May et al. (2014) }\end{array}$ \\
\hline WSOA & $0.33 \pm 0.31$ & $0.039-0.109(\mathrm{TL})$ & Akagi et al. (2011) \\
\hline WSA & $0.05 \pm 0.05$ & $0.08-0.13(\mathrm{TL}),-0.55(\mathrm{TL})$ & Akagi et al. (2011), Andreae and Merlet (2001) \\
\hline WSI & $2.10 \pm 1.34$ & $1.84-4.9(\mathrm{AR}), 0.8-1.31(\mathrm{TL}), 0.43-1.63$ (AR) & Li et al. (2007), Akagi et al. (2011), Hayashi et al. (2014) \\
\hline THM & $0.06 \pm 0.05$ & $0.06-0.09(\mathrm{AR})$ & Li et al. (2007) \\
\hline PAHs $\left(\times 10^{3}\right)$ & $4.38 \pm 3.15$ & $-17(\mathrm{AR}), 0.72-1.64(\mathrm{AR}),-9.0(\mathrm{~W})$ & $\begin{array}{l}\text { Dhammapala et al. (2007a), Zhang et al. (2011), } \\
\text { Lee et al. (2005) }\end{array}$ \\
\hline Phenols $\left(\times 10^{3}\right)$ & $24.31 \pm 12.11$ & $-35(\mathrm{AR}),-5(\mathrm{AR}),-13(\mathrm{TL})$ & $\begin{array}{l}\text { Dhammapala et al. (2007a), Hays et al. (2005), } \\
\text { Andreae and Merlet (2001) }\end{array}$ \\
\hline
\end{tabular}

AR: agricultural residue; TL: total, including forest fires and straw burning; W: wood.

2005; Gao et al., 2003). Acetic acid followed by methysulfonic acid contributed the most of the measured low molecule weight acids. Oxalic acid is the dominant dicarboxylic acid measured in the ambient environment and biomass burning aerosol (Falkovich et al., 2005; Kundu et al., 2010), and oxalic acid EF was measured to be $2.2-4.8$ and $1.6-3.6 \mathrm{mg} \mathrm{kg}^{-1}$ for smoke $\mathrm{PM}_{2.5}$ and $\mathrm{PM}_{1.0}$ in the present work. The sums of WSOA EFs ranged from 46.7 to $770.0 \mathrm{mg} \mathrm{kg}^{-1}$. Correlation among the multi-pollutants was analysed by relevance matrix as shown in Table S10. A strong positive linear relationship $\left(R^{2}>0.99, p<0.05\right.$ at $\left.95 \% \mathrm{CI}\right)$ between WSOA and emissions of OC and PM was observed. Studies have confirmed that organic acids contribute a significant fraction of both oxygenated volatile organic compounds (OVOCs) in the gaseous phase and SOA in the particulate phase; the direct emission of particulate organic acids from biomass burning also represents a significant source of precursors for SOA formation, as the low molecular organic acids will evaporate into the gas phase or be involved in the heterogeneous reaction directly (Takegawa et al., 2007; Veres et al., 2010; Yokelson et al., 2007; Carlton et al., 2006). Moreover, as a significant fraction of water-soluble organic carbon, organic acids are a major response to the $\mathrm{CCN}$ activity of smoke particles, and organic acid coating or mixing can amplify the hygroscopic growth of inorganic salts by decreasing the deliquescence $\mathrm{RH}$, enabling the particle to be a $\mathrm{CCN}$ at a relatively low degree of supersaturation (Falkovich et al., 2005; Ghorai et al., 2014). In the ambient environment, organic acids can enhance atmospheric new particle formation by impairing the nucleation barrier (Zhang et al., 2004). Besides, particulate organic acids can also mobilize the solubility of min- eral species, like iron, altering the chemical process of particles (Cwiertny et al., 2008). Prominent optical properties of organic acids like humic or fulvic substances make them potential contributors to global warming (Yang et al., 2009; Andreae and Gelencsér, 2006).

\subsubsection{Water-soluble aminiums}

Interest has been focused on the vital role of amines in the particle nucleation-growth process and acidity regulation due to their strong base (Tao et al., 2016; Bzdek et al., 2010, 2011). Though ultratrace gaseous amines and particulate aminiums were on the order of pptv or $\mathrm{ng} \mathrm{m}^{-3}$, aminium salts exhibit potential climatic and health effect due to their significantly different properties in hygroscopicity, optics, and also toxicology (Qiu and Zhang, 2012; Qiu et al., 2011; Samy and Hays, 2013; Zheng et al., 2015; Ho et al., 2015; Tao et al., 2016). It has been proposed that biomass burning is an important source for gaseous amines, especially from smoldering burning, and alkyl amides, in particular, can serve as biomarkers (Ge et al., 2011; Ho et al., 2015; Lee and Wexler, 2013; Lobert et al., 1990; Simoneit et al., 2003). However, studies have rarely quantitatively explored the particulate water-soluble amine salts (WSAs) in primary smoke emissions (Schade and Crutzen, 1995; Ge et al., 2011). From this study, WSA contributed about $4.81 \mathrm{wt} \%$ of smoke $\mathrm{PM}_{2.5}$ and $4.69 \mathrm{wt} \%$ of $\mathrm{PM}_{1.0}$, implying that aminium tends to be abundant in the fine mode of smoke particles, especially in $\mathrm{PM}_{2.5-1.0}$. $\mathrm{DEAH}^{+}, \mathrm{TMAH}^{+}, \mathrm{TEOH}^{+}$, and $\mathrm{DMAH}^{+}$made up over $80 \mathrm{wt} \%$ of the measured WSA. The fuel dependence of the WSA distribution and emissions was evident. 
EFs of WSA ranged from 4.5 to $104.8 \mathrm{mg} \mathrm{kg}^{-1}$ in smoke $\mathrm{PM}_{2.5}$. The smallest was from the burning of soybean straw and the largest from cotton and rice straw. We used the mass ratio of WSA to $\mathrm{NH}_{4}^{+}$to denote the enrichment of aminium in the particulate phase. Statistical analysis showed that $\mathrm{WSA} / \mathrm{NH}_{4}^{+}$was $0.16 \pm 0.03$ and $0.18 \pm 0.06$ in smoke $\mathrm{PM}_{1.0}$ and $\mathrm{PM}_{2.5}$, respectively, which was almost 1 order of magnitude larger than that in the ambient aerosol (Liu and Bei, 2016; Tao et al., 2016). Tao et al. (2016) measured the ratio as a function of particle size during new-particle formation days in Shanghai, and a noticeable enrichment of aminiums for ultrafine particles $(<56 \mathrm{~nm})$ was observed with WSA/ $\mathrm{NH}_{4}^{+}$over 0.2 , highlighting the competition between amines and ammonia in particle nucleation and the initial growth of nuclei. The ratio was then decreased with the increasing particle size, and the final increasing trend was found after $\sim 1.0 \mu \mathrm{m}$. The average $\mathrm{WSA} / \mathrm{NH}_{4}^{+}$for ambient bulk $\mathrm{PM}_{1.0}$ and $\mathrm{PM}_{2.5}$ was 3.2 and $3.5 \%$, respectively.

\subsubsection{PAHs and phenols}

Atmospheric PAHs are primarily the byproduct of incomplete combustion of biomass and fossil fuels (Simcik et al., 1999; Galarneau, 2008). Due to their high degree of bioaccumulation and carcinogenic or mutagenic effect, the sources and environmental fate of the ubiquitous PAHs have been the subject of extensive studies (Santodonato, 1997; Kim et al., 2013). PAHs can be involved in the photochemical reaction to form SOA. The process is influenced by gas-to-particle partitioning and meteorological conditions. Moreover, oxidation may increase the toxicity of PAHs (Arey and Atkinson, 2003; Wang et al., 2011). Biomass burning is one of the main sources of gaseous and particulate PAHs, which even contributes to about half of anthropogenic PAH emissions in China (Xu et al., 2006; Zhang et al., 2011). Burning conditions can significantly influence the emission of PAHs. In the flaming phase in this study, PAHs contributed $0.46 \mathrm{wt} \%$ of smoke $\mathrm{PM}_{2.5}$ and $0.28 \mathrm{wt} \%$ of $\mathrm{PM}_{1.0}$. Over $60 \%$ of the total PAHs were associated with respiratory submicron particles. The sum of the EFs of 16 PAHs in smoke $\mathrm{PM}_{2.5}$ ranged from 1.81 to $8.30 \mathrm{~m} \mathrm{~kg}^{-1}$, which was consistent with the values from the literature (Dhammapala et al., 2007a, b; Lee et al., 2005; Zhang et al., 2011). Hays et al. (2005) estimated total EFs of 16 PAHs to be $3.3 \mathrm{mg} \mathrm{kg}^{-1}$ in wheat straw burning $\mathrm{PM}_{2.5}$. Korenaga et al. (2001) measured PAH EFs from rice straw burning to be $1.9 \mathrm{mg} \mathrm{kg}^{-1}$ in the particulate phase, while the value from Jenkins et al. (1996) was $16 \mathrm{mg} \mathrm{kg}^{-1}$. Dhammapala et al. (2007b) found a negative linear response of biomass burning source PAH emissions to burning efficiency, and under flaming combustion, the total particulate 16 PAH EFs were $2-4 \mathrm{mg} \mathrm{kg}^{-1}$. Zhang et al. (2011) simulated the burning of rice, corn, and wheat straw. The corresponding PAH EFs were measured as 1.6, 0.9, and $0.7 \mathrm{mg} \mathrm{kg}^{-1}$ in fine-smoke particles, respectively. Great uncertainties for PAH EFs were evident that relied on burning phase, fuel types, moisture content, and also measurement techniques. Dhammapala et al. (2007a) also found that laboratory simulation might overestimate the emission factors of PAHs compared with field burning. EFs for individual PAHs were included in Tables S8 and S9. The distribution of particulate PAH emission factors was presented in Fig. 3a. Of the particle-bound PAHs, three- to four-ring components were the primary ones, including Pyr, Ant, Ace, Flu, Phe, and $\mathrm{Chr}$. Concentration ratios of selected PAHs, i.e. diagnostic ratios, were usually used to trace the source and apportion specific pollution (Yunker et al., 2002; Simcik et al., 1999). In this work, average Ant / (Ant + Phe), Flu / (Flu + Pyr), $\mathrm{BaA} /(\mathrm{BaA}+\mathrm{Chr})$, and IP / (IP + BghiP) ratios of five types of agricultural residue burning smokes were $0.72,0.36,0.47$, and 0.58 , respectively. There was no significant difference $(P<0.05$ at $95 \% \mathrm{CI})$ of the ratios in $\mathrm{PM}_{1.0}$ and $\mathrm{PM}_{2.5}$. According to previous work, Ant / (Ant + Phe) above 0.1 and $\mathrm{BaA} /(\mathrm{BaA}+\mathrm{Chr})$ above 0.35 indicate the dominance of combustion and pyrolytic sources, Flu / (Flu + Pyr) and IP / (IP + BghiP) ratios greater than 0.50 suggest that coal or biomass burning dominate (Simcik et al., 1999; Yunker et al., 2002). However, the validation of source apportionment using specific diagnostic ratios should have its constraints because of variations in source strengths and atmospheric processing of PAHs (Arey and Atkinson, 2003; Galarneau, 2008).

From Table S10, PAHs in smoke particles were highly correlated with EC and OC contents. PAHs primarily originate from the pyrolysis of organic materials during combustion, and formation mechanisms of PAHs and soot are closely linked in flames. High-molecular-weight PAHs (>500 atomic mass unit) act as precursors of soot particles (Lima et al., 2005; Richter and Howard, 2000). Thus, PAHs with three, four, and five rings accumulate and dominate in the emissions of biomass burning, as larger-molecularweight PAHs tend to be incorporated into soot particles. PAH expulsion-accumulation in OC and EC fractions was analysed by the linear fitting of PAH mass fractions and EC mass fractions in carbonaceous materials $(\mathrm{EC}+\mathrm{OC})$ in Fig. $3 b$. The partitions can be parameterized as Eq. (10):

$$
\begin{aligned}
f_{\mathrm{PAHs}} & =\frac{m_{\mathrm{PAHs}}}{m_{\mathrm{OC}}+m_{\mathrm{EC}}}=\beta_{\mathrm{EC}} \times \frac{m_{\mathrm{EC}}}{m_{\mathrm{OC}}+m_{\mathrm{EC}}}+\beta_{O C} \\
& \times \frac{m_{\mathrm{OC}}}{m_{\mathrm{OC}}+m_{E C}}=\beta_{\mathrm{EC}} \times f_{\mathrm{EC}}+\beta_{\mathrm{OC}} \times f_{\mathrm{OC}},
\end{aligned}
$$

where $f_{\mathrm{EC}}$ and $f_{\mathrm{OC}}$ are the mass fraction of $\mathrm{OC}$ and $\mathrm{EC}$ in carbonaceous materials $(\mathrm{EC}+\mathrm{OC}) . \beta_{\mathrm{EC}}$ and $\beta_{\mathrm{OC}}$ are expulsion-accumulation coefficients of PAHs in OC and BC. The coefficient of $\beta_{\mathrm{EC}}$ is $1.1 \times 10^{-3}$ in smoke $\mathrm{PM}_{1.0}$ and $1.9 \times 10^{-3}$ in $\mathrm{PM}_{2.5}$; the corresponding $\beta_{\mathrm{OC}}$ is $0.3 \times 10^{-3}$ and $0.5 \times 10^{-3}$.

Phenols are the most common SOA precursor or product and organic pollutants in the atmosphere (Berndt and Böge, 2006; Schauer et al., 2001). The hydroxyl functional group and aromatic benzene ring make phenols a 

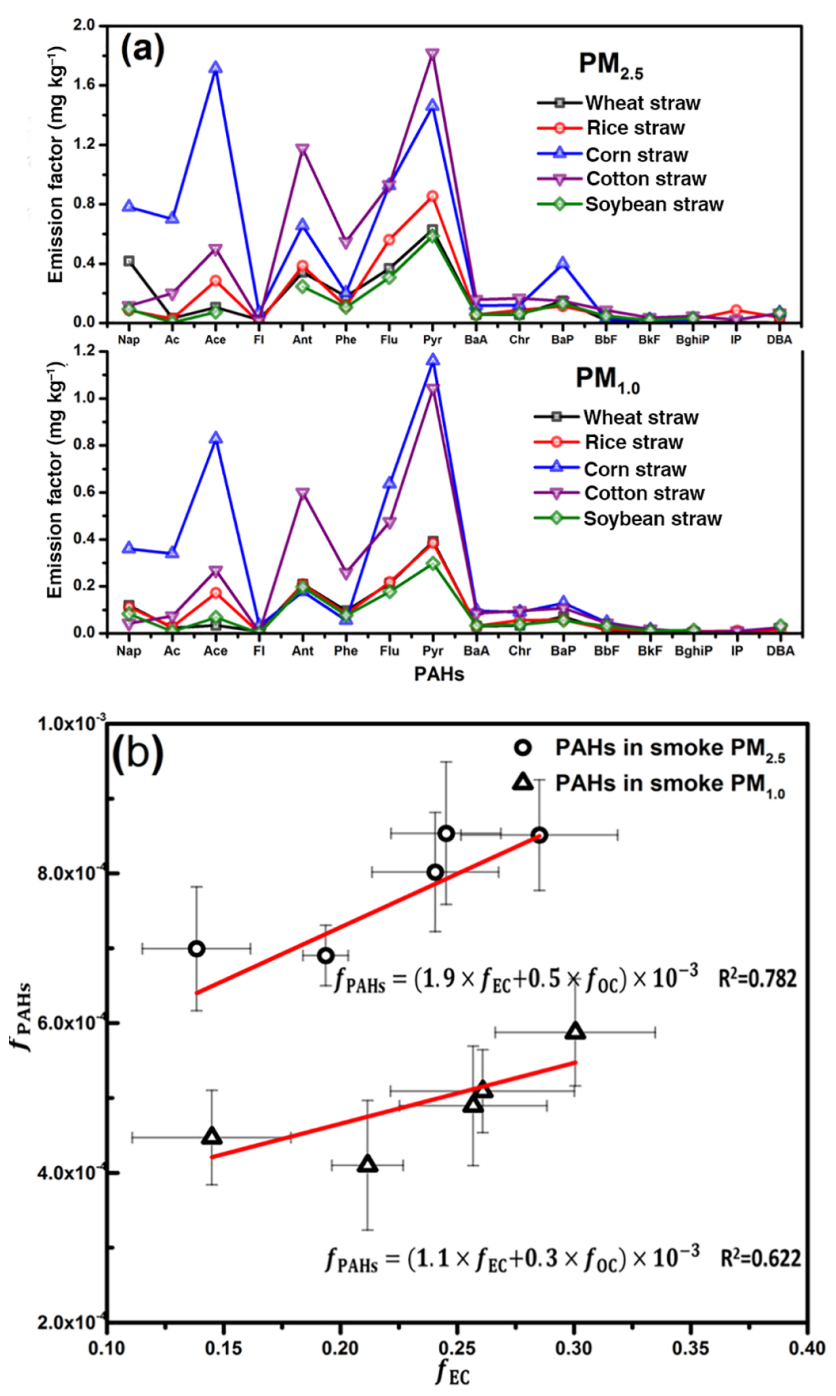

Figure 3. (a) Emission factors of 16 US EPA priority PAHs in smoke $\mathrm{PM}_{2.5}$ and $\mathrm{PM}_{1.0}$; (b) expulsion-accumulation of PAHs in $\mathrm{OC}$ and EC of smoke $\mathrm{PM}_{2.5}$ and $\mathrm{PM}_{1.0}$.

paradigm for research on the heterogeneous reaction upon photo-oxidation and aqueous phase reaction. Phenols are also ROS (reactive oxidized species) precursors that present a health hazard (Bruce et al., 1987). Phenol and substituted phenols are thermal products of lignin pyrolysis during biomass burning (Dhammapala et al., 2007a), and the most abundant methoxyphenols can be markers of biomass burning sources (Urban et al., 2016). The five measured phenols contributed 3.0 and $2.5 \mathrm{wt} \%$ of $\mathrm{PM}_{2.5}$ and $\mathrm{PM}_{1.0}$. 2, 6-Dimethoxyphenol was the major measured phenol. The mass fraction of phenols was about 7-9 times that of PAHs in smoke aerosols. EFs for the sum phenols were 9.741.5 and 7.7 and $23.5 \mathrm{~m} \mathrm{~kg}^{-1}$ for smoke $\mathrm{PM}_{2.5}$ and $\mathrm{PM}_{1.0}$, respectively. Dhammapala et al. (2007a) estimated particulate methoxyphenols emissions to be $35 \pm 24 \mathrm{mg} \mathrm{kg}^{-1}$ for wheat straw burning, while Hays et al. (2005) measured the same compounds to be $6.8 \mathrm{mg} \mathrm{kg}^{-1}$. Carbonaceous materials like PAHs and phenols or aromatic and phenolic deviates are the main chromophores in the atmosphere, and the considerable fractions of PAHs and phenols justify biomass burning as a significant source of brown carbon (Laskin et al., 2015). A study has proved that $\sim 50 \%$ of the light absorption in the solvent-extractable fraction of smoke aerosol can be attributed to these strong $\mathrm{BrC}$ chromophores (Lin et al., 2016).

\subsubsection{Inorganic components}

From Fig. 2, smoke particles consisted of approximately $24 \mathrm{wt} \%$ water-soluble inorganics (WSIs), and the inorganic salts resided more in submicron particles. A great amount of inorganics enables smoke particles to be efficient $\mathrm{CCN}$, and the distinct optical scattering characteristics of the inorganic fractions may neutralize the warming effect of brown carbon for smoke aerosol; otherwise, inorganic coating or mixing will enhance the light absorption of $\mathrm{BC} . \mathrm{K}^{+}, \mathrm{NH}_{4}^{+}$, $\mathrm{Cl}^{-}$, and $\mathrm{SO}_{4}^{2-}$ were the principle inorganic ions. Particulateenriched $\mathrm{K}^{+}$together with levoglucose are treated as tracers of a pyrogenic source (Andreae et al., 1998). The specific mass ratio of $\mathrm{K}^{+} / \mathrm{OC}$ or $\mathrm{K}^{+} / \mathrm{EC}$ will help carry out source apportionment of particulate pollutants with PMF (positive matrix factorization) and PFA (principle balance analysis) models (Lee et al., 2016). $\mathrm{K}^{+} / \mathrm{OC}$ in smoke particles ranged from 0.11 to 0.25 with an average value of 0.17 in $\mathrm{PM}_{1.0}$ and 0.14 in $\mathrm{PM}_{2.5}$, which was similar to the values reported for the savannah and agricultural waste burning emissions in India and China (Echalar et al., 1995; Ram and Sarin, 2011; Li et al., 2015). However, OC represents a large uncertainty rise from the degree of oxidization and burning conditions. $\mathrm{K}^{+} / \mathrm{EC}$ is a more practical parameter to distinguish between the pyrogenic pollutants in an ambient study. Of the smoke particles emitted from flaming fires, $\mathrm{K}^{+} / \mathrm{EC}$ was $0.58 \pm 0.24$ in $\mathrm{PM}_{1.0}$ and $0.53 \pm 0.18$ in $\mathrm{PM}_{2.5}$. $\mathrm{Cl}^{-}$was the main anion to balance the charge of WSI in smoke particles. The mean charge ratio of $\mathrm{Cl}^{-} / \mathrm{K}^{+}$was 1.46 and 1.49 in $\mathrm{PM}_{1.0}$ and $\mathrm{PM}_{2.5}$, implying that surplus chloride will associate with other cations. With atmospheric aging, the $\mathrm{Cl} / \mathrm{K}$ ratio will decrease as chloride is replaced by secondary sulfate and nitrate ( $\mathrm{Li}$ et al., 2003, 2015). The equivalent charge ratio of primary cations $\left(\mathrm{NH}_{4}^{+}+\mathrm{K}^{+}\right)$to primary anions $\left(\mathrm{SO}_{4}^{2-}+\mathrm{Cl}^{-}\right)$was 1.05 in $\mathrm{PM}_{1.0}$ and 1.01 in $\mathrm{PM}_{2.5}$ on average, and charge ratios of total cations to anions $\left(R_{\mathrm{C} / \mathrm{A}}\right)$ were 1.09 and 1.07 in $\mathrm{PM}_{1.0}$ and $\mathrm{PM}_{2.5} . R_{\mathrm{C} / \mathrm{A}}$ was used to indicate the neutralizing level of particulate matter in many studies. $R_{\mathrm{C} / \mathrm{A}} \geq 1$ indicates that most of the acids can be neutralized, while $R_{\mathrm{C} / \mathrm{A}}<1$ means atmospheric ammonia is deficient and the aerosol is acidic (Adams et al., 1999; He et al., 2012; Kong et al., 2014). In an ambient environment, acidic aerosol was the prevalent urban pollutant in many cities as shown by field investigation (He et al., 2012; Kong et al., 2014). Acidic aerosols can increase the risks to human health and affect atmospheric chemistry by 
activating hazardous materials and promoting the solubility of particulate iron and phosphorus (Amdur and Chen, 1989; Meskhidze, 2005). The emission and transport of biomass burning particles may neutralize the acidity of ambient particles. However, only limited WSI were brought into in the analytical system; it is not possible to establish the acidity or base of smoke particles, considering the existence of large organic acids and aminiums.

Trace mineral elements have attracted great attention due to their role as a catalyst in atmospheric heterogeneous reaction and their effects on health (Davidson et al., 2005; Dentener et al., 1996). Wet or dry deposition of particles during long-range transport will affect the ecological balance by releasing mineral elements (Jickells et al., 2005). Dust storm, weathering, and industrial processes are the main sources of particulate metals, and incineration can also produce a lot of mineral elements (Moreno et al., 2013). However, the emissions of trace metals from biomass burning are highly uncertain ( $\mathrm{Li}$ et al., 2007; Zhang et al., 2012). The great influence from the local soil environment and soil heavymetal pollution will certainly affect the metal content in biomass fuel and smoke particles. In this study, THM resided more in $\mathrm{PM}_{2.5}$ than in $\mathrm{PM}_{1.0}$. Smoke $\mathrm{PM}_{2.5}$ consisted of $6.7 \mathrm{wt} \%$ THM on average. $\mathrm{PM}_{1.0}$ comprised $4.1 \mathrm{wt} \%$ o THM. Average EFs of THM in $\mathrm{PM}_{2.5}$ and $\mathrm{PM}_{1.0}$ were 0.056 and $0.028 \mathrm{~g} \mathrm{~kg}^{-1}$ in this work, of which $\mathrm{Al}$ contributed over $90 \mathrm{wt} \%$, in line with results from the domestic burning of wood and field investigation of crop straw burning (Li et al., 2007; Zhang et al., 2012). Smoke particles from wheat, rice, and corn straw contained more mineral elements than those from cotton and soybean residue combustion. Regardless of the difference in biomass fuels, the result may imply that soil heavy-metal pollution is heavier in east China than that in Xinjiang in the northwest of China (Wei and Yang, 2010).

\subsection{Size, morphology, and mixing state of smoke particles}

Fresh smoke particles exhibited a unimodal size distribution within $500 \mathrm{~nm}$ (Fig. S3), and a previous chamber study also confirmed that agricultural fire produces a large amount of ultrafine particles, suggesting its great potential role as $\mathrm{CCN}$ and as a very profound threat to human health (Araujo et al., 2008; Delfino et al., 2005; Zhang et al., 2011). However, the role of particles in the atmospheric process and health hazard depends not only size but also morphology and chemical mixing states (Dusek et al., 2006; Kennedy, 2007; Mikhailov et al., 2006; Schlesinger, 1985). From the transmission electron microscope (TEM) images in Fig. 4, agricultural straw burning aerosols comprised a broad class of morphological and chemically heterogeneous particles. Non-uniform internal mixing of the agglomerates was noticeable, including the major carbonaceous particles and a considerable amount of inorganic salt particles, which was consistent with previous particulate chemical analysis. $\mathrm{KCl}$ particles containing mi- nor sulfate or nitrate were the primary inorganic particles, which presented the crystal or amorphous state from X-ray diffraction analysis (Fig. 4a-c). Potassium-bearing particles have been used as a tracer of ambient biomass burning pollutants. Fly ash particles were distinctive due to a visible morphological difference and mineral chemical composition (Fig. 4d-f). Fly ash particles were more compact and rich in mineral elements like $\mathrm{Ca}, \mathrm{Si}, \mathrm{Fe}, \mathrm{Al}, \mathrm{Mn}$, and $\mathrm{Cr}$. $\mathrm{Be}$ sides, these particles had a larger size; the statistical average diameter of fly ash particles obtained from bulk analysis was $2.2 \pm 1.6 \mu \mathrm{m}$. The result also proved that heavy metals resided more in $\mathrm{PM}_{2.5}$ than in $\mathrm{PM}_{1.0}$. Fly ash is a byproduct of the incineration process (Buha et al., 2014), including the coagulation of fuel issue debris, the condensation of evaporated mineral metal from biomass fuels, or dirt adhering in different burning phases. These fly ashes coated by or agglomerated with carbonaceous materials were like a mixture of minerals without a clear lattice structure. Tar balls as a specific form of brown carbon and soot were representative particles of biomass burning aerosol (Wilson et al., 2013; Chakrabarty et al., 2010; Tóth et al., 2014). As can be seen in Fig. 4g, chain-like soot particles coagulated with tar balls. Soot particles were agglomerates of small, roughly spherical elementary carbonaceous particles. These chemically consistent particles were within $20-30 \mathrm{~nm}$, and highresolution TEM showed that the soot spheres consisted of concentrically wrapped graphitic layers, while monomeric tar balls possessed a disordered microstructure. Tar balls and soot corresponded to different stages in the aging of organic particles; tar balls are abundant in fresh or slightly aged biomass smoke and are formed by gas-to-particle conversion of high-molecular-weight organic species or from aged primary tar droplets on biomass burning. Soot represents more aged carbon-bearing particles, formed from the pyrolysis of lignin, cellulose, or tar balls (Pósfai, 2004; Tóth et al., 2014). The botryoid aggregates in Fig. $4 \mathrm{~g}$ can be viewed as a transformation of tar balls to soot. Tar balls and soot were also internal mixed with inorganic salt including sulfate and nitrate (Fig. $4 \mathrm{~g}-\mathrm{i}$ ), which made the physicochemical properties of $\mathrm{BC}$ even more complicated, as a study has confirmed that inorganic sulfate mixing will enhance the light absorption and hygroscopicity of BC (R. Zhang et al., 2008). The dark, ringlike shell of tar balls (Fig. 4g and h) and spot-like particles adhering to the surface of tar balls (Fig. 4i) were K-rich materials. The size of soot particles was mainly within $200 \mathrm{~nm}$, while tar balls and other carbonaceous particles can be over $1 \mu \mathrm{m}$.

\subsection{Open-burning emissions}

\subsubsection{Crop straw production}

The agricultural straw production was calculated and is geodisplayed graphically in Fig. 5a-c. In total, $647.3 \mathrm{Tg}$ of agricultural straw was produced in 2012, mainly in the north 


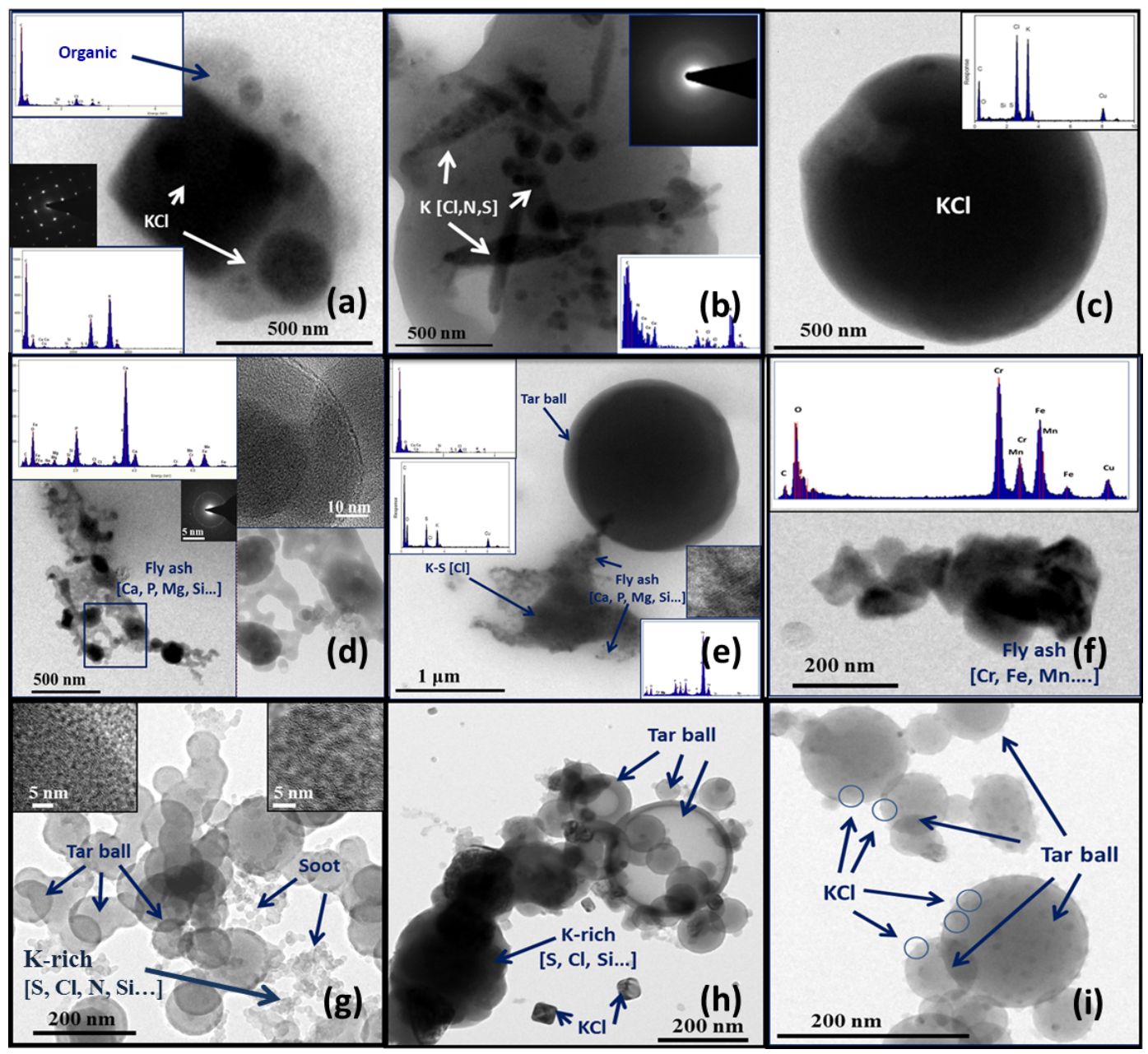

Figure 4. Transmission electron microscope (TEM) images and EDX analysis of fresh agricultural residue burning particles. (a)-(c) Crystal and amorphous $\mathrm{KCl}$ particles internally mixed with sulfate, nitrate, and carbonaceous materials. (d)-(f) Heavy-metal-bearing fractal-like fly ash particles. (e)-(g) Chain-like soot particles and tar balls.

and northeast of China. The distributions of the straw clearly correspond to the distinct planting regions that are divided by the Qin Ling Mountain-Huai He line and the Yangtze River. Rice is primarily planted in the south of the Qin Ling Mountain-Huai He line. Only 10\% rice (single-cropping rice dominates) is planted in Heilongiiang, Jilin, and Liaoning province, while wheat and corn are grown mostly to the north of the Yangtze River. Over $90 \%$ of the wheat planted in China is winter wheat that is ripe in summer, and more than $80 \%$ of rice, including middle and late rice, becomes mature in autumn. The summer harvest contributed about $25 \%$ of the agricultural straw production, which consists solely of rice and wheat straw in this period and is distributed uniformly across the centre and east of China. Overall, $493.9 \mathrm{Tg}$ crop straw was produced mainly from corn and rice harvesting in autumn. Soybean and cotton straw accounts for about $8.6 \%$ of autumn straw production and was primarily produced in Heilongjiang and Xinjiang province.

\subsubsection{Open-burning rate}

The five scenarios of field burning rates and regional AIP $\left(\frac{I_{k, y}}{\mathrm{Al} k_{k, y}}\right)$ in the years 2000, 2006, and 2012 are listed in Table 4 and statistically analysed in Fig. 6. A significant difference $(P<0.05$ at $95 \% \mathrm{CI})$ in regional burning rates among the scenarios was observed, and the rates from the NDRC report were generally higher. For convenience, six zones were classified by geographic divisions and economic areas in China, including the North Plain of China (NPC: Anhui, Shandong, Hebei, Shanxi, Tianjin, Beijing), the centre of China (CC: Hunan, Henan, Hubei), the Yangtze River delta (YRD: Zhejiang, Jiangsu, Shanghai), the northeast of China (NC: Heilongjiang, Liaoning, Jilin), the Pan-Pearl River delta (PRD: Hainan, Guangdong, Fujian, Guangxi, Guizhou, Sichuan, Yunnan, Jiangxi), and the west of China (WC: Shaanxi, Chongqing, Xinjiang, Qinghai, Ningxia, Tibet, Inner Mongolia, Gansu). The average bulk-weighted 
burning rates from BAU, EM, and NDRC versions for the six zones were $22.3 \% \pm 3.1 \%, 21.1 \% \pm 3.3 \%, 28.4 \% \pm 6.2 \%$, $23.3 \% \pm 9.2 \%, 21.4 \% \pm 6.5 \%$, and $14.2 \% \pm 8.0 \%$, respectively. It was obvious that agricultural field burning was most widespread in the Yangtze River delta, especially in Zhejiang province. The nationwide field burning rate was 21.4, 16.3, 26.0, 14.9, and $26.8 \%$ for BAU-I, BAU-II, EM-I, EM-II, and NDRC, respectively, which was comparable with the documented values (Daize, 2000; Wei et al., 2004; H. Zhang et al., 2008).

\subsubsection{Agricultural open-burning emissions}

$\mathrm{PM}_{2.5}$ emissions from agricultural field burning based on BAU, EM, and NDRC versions were calculated and are geographically presented in Fig. 7 (emissions of detailed individual species in the Supplement). A similar spatial character of regional emission distribution was observed for the BAU, EM, and NDRC versions. Most emissions were allocated to the North Plain and the centre of China, where the primary agricultural regions are located, reflecting the agricultural fire sites in Fig. S2. Although field burning rates were higher in the Yangtze River delta, the crop residue production in this zone was much less, and the region only contributed $4.3 \%$ of the national straw production. Taking NDRC as the basis, the BAU and EM scenarios underestimated the emissions in the northeast of China, especially in Heilongjiang.

The temporal distributions of field burning emissions also reflected the crop residue production and the agricultural fire sites in summer and autumn harvest. Apart from Henan and Tibet, where the main crop straw was produced in summertime, more pollutants were emitted in the autumn harvest period to the other regions, which has been confirmed by many studies (He et al., 2011; Wang and Zhang, 2008). The largescale field burning emissions in autumn exhibited great influence on the haze formation and visibility degradation in the north and east of China (Leng et al., 2014; Shi et al., 2014), K. Huang et al. (2012) has identified biomass burning together with secondary inorganic aerosol (SIA) and dust pollution as three typical haze types in Shanghai. In summertime, field burning emissions were concentrated in the North Plain, the centre, and the southern regions, while in the autumn, the emissions became more ubiquitous and widespread in the northeast of China.

Nationwide emission inventories and flux concentrations are displayed graphically in Fig. 8 and presented in Table 5. The total $\mathrm{PM}_{2.5}$ emission from agricultural field burning was $738.36-1241.69 \mathrm{Gg}$ in 2012 , and rice, corn, and wheat straw burning made up 93.5-95.6\% of the total emissions. The largest quantities of $\mathrm{PM}_{2.5}$ emissions came from Heilongjiang, Shandong, Henan, Jilin, Jiangsu, Anhui, and Hebei. A distinct difference in the emissions from various scenarios was observed, especially for Heilongjiang province, which contributed $5.5 \%(55.4 \mathrm{Gg})$ of $\mathrm{PM}_{2.5}$ emissions under the BAU-II scenarios, while the figure was $22.9 \%(231.0 \mathrm{Gg})$ under the EM-I scenarios. Annual emissions of $\mathrm{PM}_{1.0}, \mathrm{OC}$, and EC were 661.81-1111.90, 318.84-533.19, and 98.06-164.97 Gg, respectively, which was comparable with previous studies (Cao et al., 2006, 2011; Wang et al., 2012). Qin and Xie (2011, 2012) developed national carbonaceous aerosol emission inventories from biomass open burning for multi-years with dynamic burning activity. They believed BC and OC emissions followed an exponential growth from 14.03 and $57.37 \mathrm{Gg}$ in 1990 to 116.58 and $476.77 \mathrm{Gg}$ in 2009. Cao et al. (2006, 2011) calculated smoke aerosol emissions from biomass burning in China for 2000 and 2007 using the same activity data from BAU-I scenarios. National OC and EC emissions were reported to be 425.9 and $103.0 \mathrm{Gg}$ in 2000 ; however, no evident changes were found for the emissions in 2007 , which were assessed to be 433.0 and $104.0 \mathrm{Gg}$. X. Huang et al. (2012) estimated crop burning in the fields with unified EFs and burning rate $(\sim 6.6 \%)$ for all kinds of crops across China in 2006. The estimated annual agricultural fire emissions were about 270, 100, and $30 \mathrm{Gg}$ for $\mathrm{PM}_{2.5}$, $\mathrm{OC}$, and $\mathrm{BC}$, respectively. In the present work, agricultural fire $\mathrm{PM}_{2.5}$ emissions in 2012 were allocated to six zones. The average contribution in percentage for each zone was compared: NPC $(23.1 \%) \geq \mathrm{NC}(21.6 \%)>\mathrm{PRD}$ $(18.4 \%) \geq \mathrm{CC} \quad(18.2 \%)>\mathrm{WC} \quad(9.8 \%)>\mathrm{YRD} \quad(8.8 \%)$. Further, the contribution for summertime emissions was NPC $(35.5 \%)>$ CC $(28.8 \%) \geq \operatorname{PRD}(21.1 \%)>$ YRD $(9.1 \%)>\mathrm{WC}(5.4 \%)>\mathrm{NC}(0.1 \%)$, and for the autumn harvest emissions, it was NC $(27.8 \%)>\mathrm{NPC}(19.6 \%)>\mathrm{PRD}$ $(17.6 \%)>\mathrm{CC} \quad(15.1 \%)>\mathrm{WC} \quad(11.1 \%)>\mathrm{YRD} \quad(8.8 \%)$. It was obvious that the North Plain experienced extensive crop fire emissions during the whole harvest periods, where $\mathrm{PM}_{2.5}, \mathrm{PM}_{1.0}$, OC, and $\mathrm{BC}$ emissions in 2012 were 233.6, 209.8, 102.3, and 29.4 Gg on average. Liu et al. (2015) developed emission inventories from agricultural fires in the North Plain based on MODIS fire radiative power. Emission for $\mathrm{PM}_{2.5}$, OC, and $\mathrm{BC}$ in 2012 was reported to be 102.3, 37.4 , and $13.0 \mathrm{Gg}$, respectively. However, EFs were also treated as unified values (e.g. crop burning EFs for $\mathrm{PM}_{2.5}$, $\mathrm{OC}$, and $\mathrm{BC}$ were $6.3,2.3$, and $0.8 \mathrm{~g} \mathrm{~kg}^{-1}$ ) in the work of Liu et al. (2015), who cited Akagi et al. (2011) directly without considering the fuel type dependence of EFs. Zhao et al. (2012) established comprehensive anthropogenic emission inventories for Huabei region including the North Plain, Inner Mongolia, and Liaoning province. All crop straw was assumed to be burnt in the field, resulting in much greater emissions of $446 \mathrm{Gg} \mathrm{OC}$ and $160 \mathrm{Gg} \mathrm{BC}$ in 2003. A specific temporal pattern for agricultural fire emissions was observed in the northeast of China (Heilongjiang, Liaoning, and Jilin), where the open burning mainly occurred in the autumn harvest and produced a great amount of pollutants (217.5 Gg PM $2.5, \quad 89.4 \mathrm{Gg} \mathrm{OC}$, and $29.7 \mathrm{Gg} \mathrm{EC}$ ), while emissions in the summertime can be neglected.

In 2012, 20-25\% of national emissions was released from summertime field burning, i.e. $226.0 \mathrm{Gg} \mathrm{PM}_{2.5}$, 


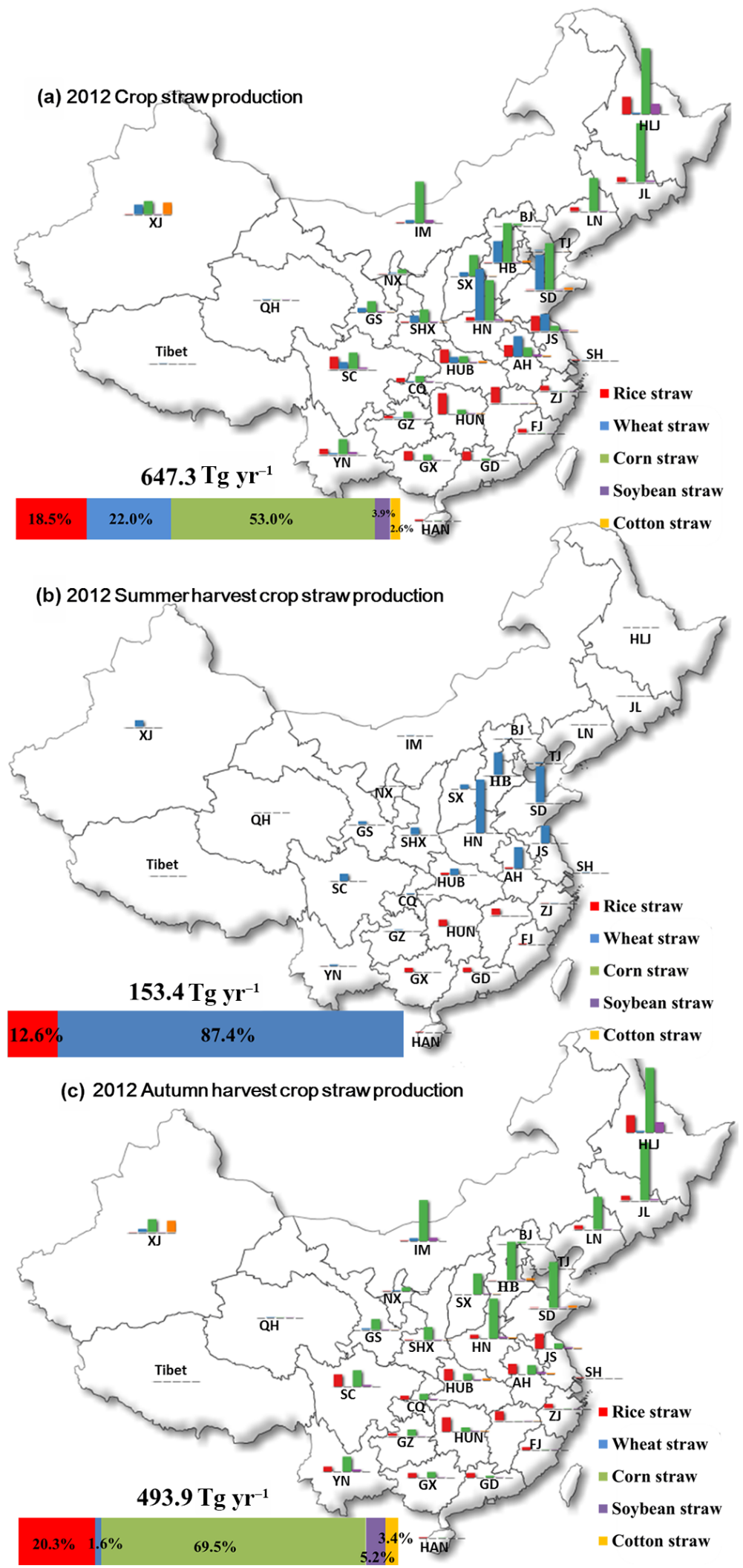

Figure 5. Annual agricultural residue production of five major crops allocated to two harvests (summer and autumn harvest) based on agricultural yield in China in 2012. 
Table 4. Summary of field burning rates and economic data in China.

\begin{tabular}{|c|c|c|c|c|c|c|c|c|c|}
\hline \multirow[t]{2}{*}{ Province } & \multicolumn{2}{|c|}{ Burning rate from the literature } & \multicolumn{3}{|c|}{ Agricultural income ratio ${ }^{c}$} & \multicolumn{2}{|c|}{ Estimated burning rate } & \multirow{2}{*}{$\begin{array}{c}\text { NDRC report }{ }^{\mathrm{d}} \\
\text { NDRC }\end{array}$} & \multirow[t]{2}{*}{ Average rate } \\
\hline & BAU-I ${ }^{\mathrm{a}}$ & BAU-II ${ }^{b}$ & 2000 & 2006 & 2012 & EM-I & EM-II & & \\
\hline Beijing & 0.00 & 0.17 & 0.08 & 0.06 & 0.06 & 0.00 & 0.19 & 0.13 & $0.10 \pm 0.08$ \\
\hline Hebei & 0.20 & 0.17 & 0.27 & 0.22 & 0.24 & 0.22 & 0.16 & 0.19 & $0.19 \pm 0.02$ \\
\hline Shanxi & 0.20 & 0.17 & 0.20 & 0.21 & 0.25 & 0.16 & 0.14 & 0.22 & $0.18 \pm 0.03$ \\
\hline Inner Mongolia & 0.00 & 0.12 & 0.44 & 0.49 & 0.66 & 0.00 & 0.09 & 0.27 & $0.10 \pm 0.10$ \\
\hline Heilongjiang & 0.30 & 0.12 & 0.99 & 0.83 & 0.59 & 0.50 & 0.17 & 0.25 & $0.27 \pm 0.13$ \\
\hline Shanghai & 0.00 & 0.32 & 0.10 & 0.08 & 0.09 & 0.00 & 0.29 & 0.12 & $0.15 \pm 0.14$ \\
\hline Jiangsu & 0.30 & 0.32 & 0.32 & 0.22 & 0.30 & 0.32 & 0.23 & 0.19 & $0.27 \pm 0.05$ \\
\hline Zhejiang & 0.30 & 0.32 & 0.19 & 0.08 & 0.09 & 0.64 & 0.28 & 0.22 & $0.35 \pm 0.15$ \\
\hline Anhui & 0.20 & 0.32 & 0.44 & 0.39 & 0.43 & 0.21 & 0.29 & 0.43 & $0.29 \pm 0.08$ \\
\hline Fujian & 0.30 & 0.32 & 0.18 & 0.10 & 0.14 & 0.39 & 0.22 & 0.17 & $0.28 \pm 0.08$ \\
\hline Hunan & 0.20 & 0.33 & 0.47 & 0.31 & 0.43 & 0.22 & 0.24 & 0.35 & $0.27 \pm 0.06$ \\
\hline Guangdong & 0.30 & 0.33 & 0.19 & 0.10 & 0.13 & 0.44 & 0.25 & 0.18 & $0.30 \pm 0.09$ \\
\hline Guangxi & 0.20 & 0.33 & 0.40 & 0.25 & 0.33 & 0.25 & 0.25 & 0.35 & $0.28 \pm 0.06$ \\
\hline Hainan & 0.30 & 0.33 & 0.35 & 0.16 & 0.21 & 0.51 & 0.25 & 0.56 & $0.39 \pm 0.12$ \\
\hline Chongqing & 0.20 & 0.11 & 0.35 & 0.23 & 0.30 & 0.24 & 0.08 & 0.45 & $0.22 \pm 0.13$ \\
\hline Sichuan & 0.20 & 0.11 & 0.37 & 0.22 & 0.28 & 0.26 & 0.09 & 0.30 & $0.19 \pm 0.08$ \\
\hline Guizhou & 0.20 & 0.11 & 0.38 & 0.23 & 0.25 & 0.31 & 0.10 & 0.43 & $0.23 \pm 0.13$ \\
\hline Yunnan & 0.20 & 0.11 & 0.36 & 0.26 & 0.31 & 0.24 & 0.09 & 0.28 & $0.18 \pm 0.07$ \\
\hline Tibet & 0.00 & 0.16 & 0.15 & 0.09 & 0.05 & 0.00 & 0.30 & 0.16 & $0.12 \pm 0.11$ \\
\hline Shaanxi & 0.20 & 0.17 & 0.33 & 0.27 & 0.26 & 0.25 & 0.18 & 0.28 & $0.22 \pm 0.04$ \\
\hline Gansu & 0.10 & 0.16 & 0.25 & 0.20 & 0.28 & 0.09 & 0.11 & 0.33 & $0.16 \pm 0.09$ \\
\hline Qinghai & 0.00 & 0.16 & 0.23 & 0.10 & 0.08 & 0.00 & 0.20 & 0.28 & $0.13 \pm 0.11$ \\
\hline
\end{tabular}

$205.2 \mathrm{Gg} \mathrm{PM}_{1.0}, 105.9 \mathrm{Gg}$ OC, $28.4 \mathrm{Gg} \mathrm{EC}, 6.8 \mathrm{Gg} \mathrm{WSOA}$, $1.0 \mathrm{Gg}$ WSA, $0.1 \mathrm{Gg}$ PAHs, $0.9 \mathrm{Gg}$ phenols, and $2.1 \mathrm{Gg}$ THM on average. The corresponding values for autumn harvest were $781.6,697.9,327.3,106.0,18.4,4.8,0.4,1.9$, and $6.6 \mathrm{Gg}$, respectively. Integrated smoke OC / EC was 3.7 from national summertime emission and 3.1 from autumn harvest emission. Regarding different locations, the integrated OC / EC in the North Plain was 4.1 for summertime emission and 3.2 for the autumn harvest, while $\mathrm{OC} / \mathrm{EC}$ in the centre of China was 3.1 for both summer and autumn harvest emissions, implying that the spatio-temporal characteristics of agricultural field fires have a potential influence on the composition of smoke emissions and their related physicochemical properties. Zhang et al. (2011) estimated particulate PAH emissions form three types of crop residues to be $0.46 \mathrm{Gg}$ in 2003. Xu et al. (2006) counted PAHs from all straw, assuming burning rates to be $100 \%$, and they calcu- lated 5-10 Gg PAH emissions in 2003, which was 10 times our result.

The nationwide flux concentration of smoke $\mathrm{PM}_{2.5}$ was $0.7-1.0 \mu \mathrm{g} \mathrm{m}^{-3} \mathrm{day}^{-1}$ in the summer harvest and 1.4 $3.5 \mu \mathrm{g} \mathrm{m}^{-3} \mathrm{day}^{-1}$ in autumn harvest, while average annual flux concentrations for $\mathrm{OC}$ and $\mathrm{EC}$ were 0.80 and $0.25 \mu \mathrm{g} \mathrm{m}^{-3} \mathrm{day}^{-1}$. Saikawa et al. (2009) assessed the annual concentrations of $\mathrm{OC}$ and $\mathrm{BC}$ from biomass burning primary emission in China using global models of chemical transport (MOZART-2) and concluded that they were 1.8 and $0.35 \mu \mathrm{g} \mathrm{m}^{-3}$. The most polluted areas were Anhui, Henan, Shandong, Jiangsu, Liaoning, and Hunan.

\subsubsection{Uncertainties of the emissions}

The fuzziness and uncertainties of major pollutant emissions from fuel combustion in China came from the uncertainties in source-specific emission factors and the effective consumption of bio or fossil fuel. Frey and Zhao (2004) and 


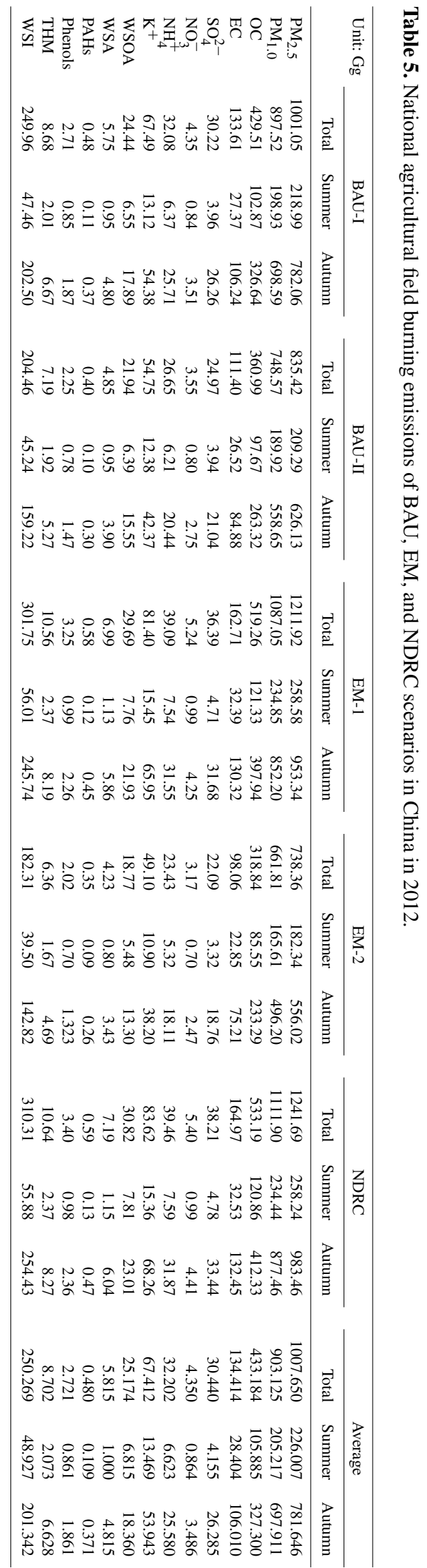

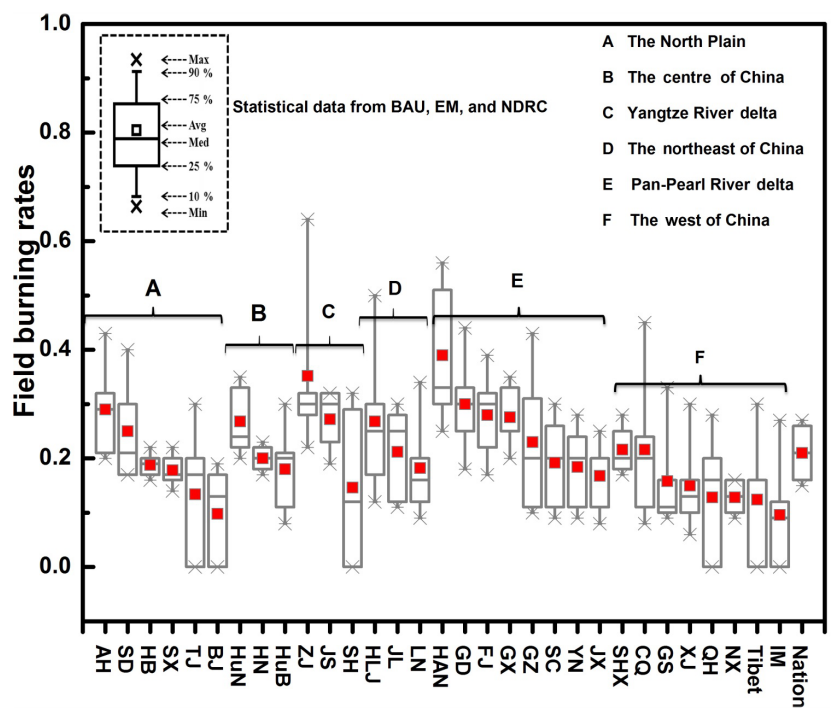

Figure 6. Statistical analysis of field burning rates from BAU, EM, and NDRC versions.

Frey and Zheng (2002) analysed uncertainties in emission factors and emissions of air-toxic pollutants and technologydependent coal-fire power plants via the bootstrap simulation method. Zhao et al. $(2011,2012)$ estimated uncertainties in national anthropogenic pollutant emissions based on a Monte Carlo simulation, and they believed that activity rates (e.g. fuel consumption) are not the main source of emission uncertainties at the national level. The uncertainties in the emission inventory can also be estimated by comparing different emission inventories for the same region and period (Ma and Van Aardenne, 2004).

In this study, we investigated the uncertainties of multipollutant emissions for agricultural residue open burning using a Monte Carlo simulation. The methodology is described in detail in Qin and Xie (2011). We followed these assumptions: a normal distribution with a coefficient of variation (CV) of $30 \%$ for the official statistics (e.g. crop production and GDP economic data obtained from the Statistic Yearbooks and field burning rates for agricultural straw derived from NDRC report), a normal distribution with $50 \% \mathrm{CV}$ for open-burning rates from the literature (BAU-I and BAU-II), and a uniform distribution with $\pm 30 \%$ deviation for the remaining activity data (crop-to-residue ratio, dry matter fraction, and burning efficiency). Regarding the emission factors, Bond et al. (2004) assumed that most particulate EFs followed lognormal distributions, with a CV of $\pm 50 \%$ for domestic EFs and of $\pm 150 \%$ for EFs obtained from foreign studies. Here, we applied the CV of smoke EFs as we measured ones which were chemical species and fuel type dependent. With randomly selected values within the respective probability density functions (PDFs) of EFs and activity data for each biomass type, Monte Carlo simulation was implemented 10000 times, and the uncertain- 

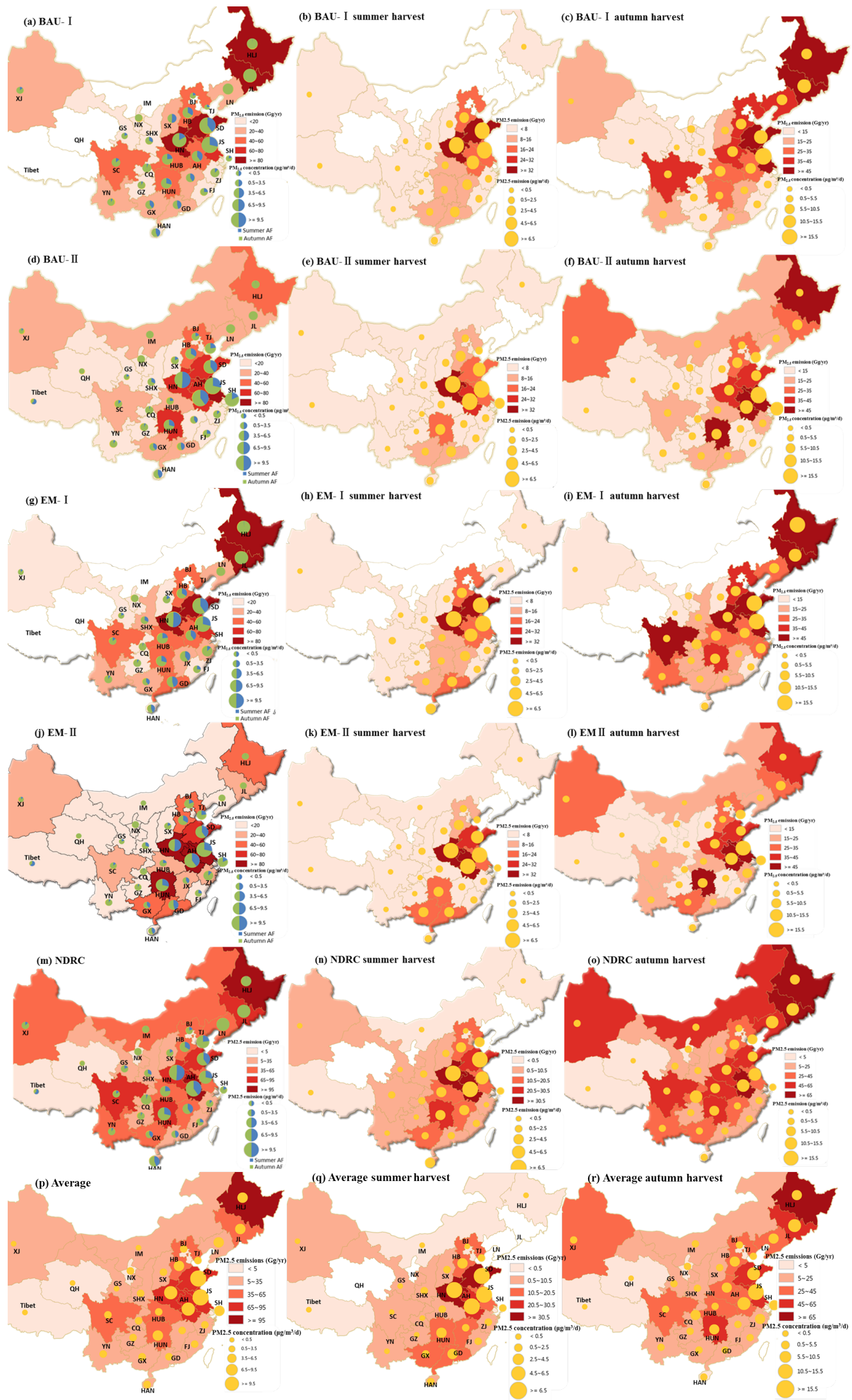

Figure 7. Spatial and temporal distribution of smoke $\mathrm{PM}_{2.5}$ emissions and flux concentrations from agricultural field burning over China in 2012. 

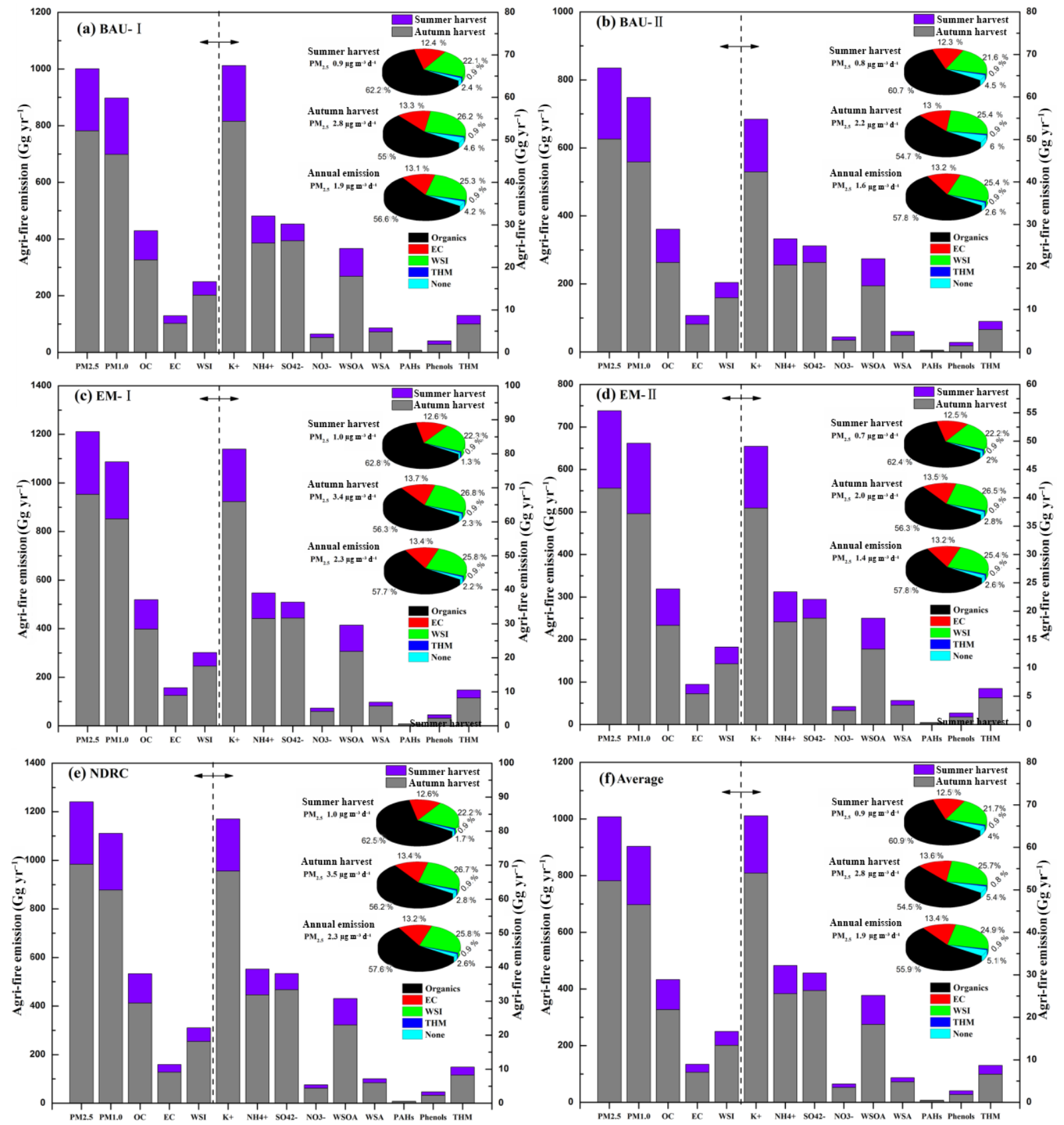

Figure 8. Nationwide $\mathrm{PM}_{2.5}$ emissions and flux concentrations based on different burning versions. The inset pie graphs are chemical compositions of integrated $\mathrm{PM}_{2.5}$ from five major agricultural residue burnings.

ties in national yearly multi-pollutant emissions at $95 \% \mathrm{CI}$ were obtained for all the five versions. Afterwards, uncertainties for the average emission inventories were assessed using the propagation of uncertainty calculation that is suggested by the IPCC (1997) (method in the Supplement), and all the emission uncertainties were presented as percentages in Table 6. Emissions for water-soluble aminiums and organic acids had great uncertainties, due to their large deviation in EFs compared with other smoke species. Besides, emissions of BAU versions were more accurate than EM versions because of more uncertainty addition in the burning rate conversion, using economic data for EM versions. Otherwise, burning rates derived from the NDRC report were assumed to have less uncertainty, resulting in the least uncertainties in smoke emission assessments. On average, for all five versions, the mean, 2.5th percentile, and 97.5th percentile values for smoke $\mathrm{PM}_{2.5}$ emissions in 2012 were 1005.7, 758.3, and $1344.6 \mathrm{Gg}$, respectively. As for OC emissions, the mean, 
2.5th percentile, and 97.5 th percentile values were 432.4 , 327.8 , and $576.4 \mathrm{Gg}$. The figures for EC were 134.2, 100.9, and $187.9 \mathrm{Gg}$. Therefore, the overall propagation of uncertainties for smoke $\mathrm{PM}_{2.5}, \mathrm{OC}$, and $\mathrm{EC}$ at $95 \% \mathrm{CI}$ was $(-24.6$, $33.7 \%),(-24.4,33.5 \%)$, and $(-24.2,33.3 \%)$, respectively. The uncertainties for OC and EC emissions were much less than in the work of Qin and Xie (2011), in which emission and uncertainties were $266.7 \mathrm{Gg}(-55.9,96.1 \%)$ for $\mathrm{OC}$ and $66.9 \mathrm{Gg}(-53.9,92.6 \%)$ for $\mathrm{EC}$ in 2005.

\subsection{Health and health-related economic impacts}

\subsubsection{Carcinogenic risk}

Calculated $\mathrm{CR}_{\mathrm{SPM}}$ for smoke $\mathrm{PM}_{2.5}$ from wheat, corn, rice, cotton, and soybean straw burning was $5.3 \times 10^{-6}$, $3.8 \times 10^{-6}, 2.6 \times 10^{-6}, 0.7 \times 10^{-6}$, and $1.3 \times 10^{-6}$ per $\mu \mathrm{g} \mathrm{m}^{-3}$, respectively. The corresponding one in a million PEL was $0.2,0.3,0.4,1.4$, and $0.8 \mu \mathrm{g} \mathrm{m}^{-3}$. Wu et al. (2009) assessed the unit risk of wood and fuel burning particles using metals only. The results were $3.2 \times 10^{-6}$ and $1.5 \times 10^{-6}$ per $\mu \mathrm{g} \mathrm{m}^{-3}$, which was close to the values in our study. In actual application, the PEL of smoke particles should be the bulk mass concentration of mixed aerosols.

It was noticeable that apart from Tibet and Qinghai, the flux concentration of smoke $\mathrm{PM}_{2.5}$ among all the five emission versions in other regions far surpassed the PEL, especially in the North Plain and the centre of China, exhibiting a great potential cancer risk from the inhalation of smoke. For health care, the emission flux concentration should be constrained within the PEL of crop straw burning aerosol. Thus the critical field burning rates can be derived to ensure risk aversion following Eq. (11):

$$
R_{k} \leq \frac{10^{-6} \times S_{k} \times h \times T_{k}}{\sum_{j} \sum_{i} P_{t, k, i} \times r_{i} \times H_{t, k, i} \times D_{i} \times f_{i} \times \mathrm{EF}_{i, j} \times \mathrm{CRF}_{i}} .
$$

The conservative values of regional field burning rates from Eq. (11) were named as carcinogenic-risk control scenarios (CRCs) and listed in Table S11; this will be instructive in emission control. Under CRCs, the national crop straw field burning rate was less than $3 \%$. Emissions of $\mathrm{PM}_{2.5}$ are geographically presented in Fig. S4, and, at most, $146.3 \mathrm{Gg} \mathrm{yr}^{-1}$ smoke $\mathrm{PM}_{2.5}$ should be released in China. The corresponding annual flux concentration of $\mathrm{PM}_{2.5}$ was within $0.3 \mu \mathrm{g} \mathrm{m}^{-3}$ day $^{-1}$ (for detailed emission inventories under CRC versions, see the Supplement).

\subsubsection{Health impacts}

Regional health impacts from acute exposure to agricultural residue burning aerosol were assessed using average daily flux concentrations of smoke $\mathrm{PM}_{2.5}$. The result is presented in Table S12. The impacts from smoke $\mathrm{PM}_{2.5}$ exposure were severest in Jiangsu, Shandong, and Henan province, where annual premature mortality was over 1000 . Overall,

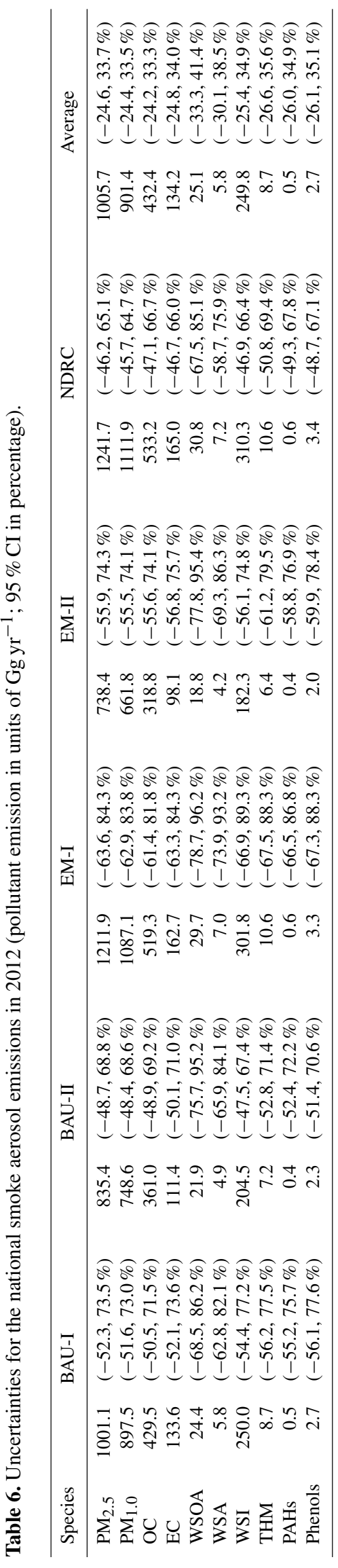

Atmos. Chem. Phys., 17, 4957-4988, 2017 
Table 7. Estimated number of cases $(95 \%$ CI $)$ attributable to agricultural fire smoke $\mathrm{PM}_{2.5}$ exposure in China in 2012.

\begin{tabular}{lrrrr}
\hline $\begin{array}{l}\text { Emission } \\
\text { version }\end{array}$ & Mortality & $\begin{array}{r}\text { Respiratory hospital } \\
\text { admission }\end{array}$ & $\begin{array}{r}\text { Cardiovascular hospital } \\
\text { admission }\end{array}$ & Chronic bronchitis \\
\hline BAU-I & $7864(3154,12489)$ & $31123(21114,40788)$ & $29454(12849,45481)$ & $7577067(2952006,11024705)$ \\
BAU-II & $7187(3056,11260)$ & $28711(19443,37693)$ & $27156(11825,42007)$ & $7132581(2735111,10523803)$ \\
EM-I & $9435(3817,14933)$ & $36950(25151,48269)$ & $35116(15373,54042)$ & $8712880(3484325,12430411)$ \\
EM-II & $6175(2554,9751)$ & $25166(17004,33112)$ & $23745(10316,36816)$ & $6383442(2407643,9526727)$ \\
NDRC & $8523(3581,13377)$ & $33957(23015,44542)$ & $32131(14003,49664)$ & $8332216(3228351,12148274)$ \\
\hline Average & $7836(3232,12362)$ & $31181(21145,40881)$ & $29520(12873,45602)$ & $7267237(2961487,1130784)$ \\
\hline CRC & $538(227,850)$ & $2191(1462,2920)$ & $2038(874,3199)$ & $636650(214617,1052153)$ \\
\hline
\end{tabular}

Table 8. Health-related economic loss (95\% CI) from agricultural fire smoke $\mathrm{PM}_{2.5}$ exposure in China in 2012.

\begin{tabular}{|c|c|c|c|c|c|c|}
\hline \multirow{2}{*}{$\begin{array}{l}\text { Emission } \\
\text { version }\end{array}$} & \multicolumn{4}{|c|}{ Economic cost (million USD) } & \multirow{2}{*}{$\begin{array}{r}\text { Total cost } \\
\text { (million USD) }\end{array}$} & \multirow{2}{*}{$\begin{array}{c}\text { GDP ratio } \\
(\% \circ)\end{array}$} \\
\hline & Mortality & $\begin{array}{r}\text { Respiratory } \\
\text { hospital } \\
\text { admission }\end{array}$ & $\begin{array}{r}\text { Cardiovascular } \\
\text { hospital } \\
\text { admission }\end{array}$ & Chronic bronchitis & & \\
\hline BAU-1 & $1544.5(730.7,2430.0)$ & $19.6(13.3,25.7)$ & $36.0(15.7,55.6)$ & $7187.6(2800.3,10458.3)$ & $8787.8(3560.0,12969.4)$ & $1.0(0.4,1.5)$ \\
\hline BAU-2 & $1453.9(719,2252.2)$ & $18.1(12.2,23.8)$ & $33.2(14.4,51.3)$ & $6766.0(2594.5,9982.9)$ & $8271.2(3340.3,12310.3)$ & $1.0(0.4,1.4)$ \\
\hline EM-1 & $1855.2(870.3,2913.7)$ & $23.3(15.9,30.5)$ & $42.9(18.8,66.1)$ & $8265.0(3305.2,11791.5)$ & $10186.5(4210.2,14801.8)$ & $1.2(0.5,1.7)$ \\
\hline Average & $1531.0(736.0,2393.9)$ & $19.7(13.3,25.8)$ & $36.1(15.7,55.7)$ & $7235.6(2809.3,10558.7)$ & $8822.4(3574.4,13034.2)$ & $1.0(0.4,1.5)$ \\
\hline CRC & $100.0(48.0,157.1)$ & $1.3(0.9,1.8)$ & $2.4(1.0,3.9)$ & $603.9(203.6,998.1)$ & $707.8(253.6,1160.9)$ & $0.1(0.1,0.1)$ \\
\hline
\end{tabular}

China suffered from 7836 (95\% CI: 3232, 12 362) premature deaths, 31181 (95\% CI: 21 145, 40 881) respiratory hospital admissions, 29520 (95\% CI: 12873, 45602 ) cardiovascular hospital admissions, and 7267237 (95\% CI: 2961 487, 1130784 ) cases of chronic bronchitis related to agricultural fire smoke in 2012, as can be seen in Table 7. According to national health statistical reports (NHFPC, 2013), the hospital admissions due to respiratory and cardiovascular disease were 5071523 in China in 2012, and smoke $\mathrm{PM}_{2.5}$ exposure might contribute $\sim 1.2 \%$ of the hospital admissions from this study. Saikawa et al. (2009) reported 70000 premature deaths in China and an additional 30000 deaths globally due to $\mathrm{OC}, \mathrm{EC}$, and sulfate exposure, which were primarily emitted from biofuel combustion in China in 2000. However, the results are likely to be overestimations not only with regard to the exaggerated pollutant emissions but also because of the iterative operations of respective species-induced mortality; moreover, the exposure-response coefficient $\beta$ and incidence rate Saikawa et al. (2009) applied from Pope III et al. (2002) and WHO (2000) were higher than the practical values from local research (Cao et al., 2012; Chen et al., 2011; Hou et al., 2012). According to Table 7, under the CRC version, over $92 \%$ mortality and morbidity can be avoided.

\subsubsection{Health-related economic losses}

Health-related total economic losses from straw openburning smoke $\mathrm{PM}_{2.5}$ exposure were assessed to be USD 8822.4 million (95\% CI: $3574.4,13034.2)$ on average, as can be seen from Table 8 , accounting for $0.1 \%$ of the total GDP in 2012, and detailed regional economic losses are listed in Table S13. Economic losses from premature death contributed about $17 \%$ of total losses, and loss from chronic bronchitis dominated. Hou et al. (2012) estimated USD 106.5 billion lost due to ambient $\mathrm{PM}_{10}$ exposure in China in 2009; even a severe haze episode (the focus of which is $\mathrm{PM}_{2.5}$ ) in January 2013 may have caused 690 premature death and a USD 253.8 million loss in Beijing, and source-specification analysis stressed the emission from biomass burning (Yang et al., 2015; Gao et al., 2015). It was obvious that smoke $\mathrm{PM}_{2.5}$ contributed a noticeable damage to public health and social welfare. According to the CRC version estimation, the carcinogenic-risk control policy can prevent over $92 \%$ of the economic loss.

\section{Conclusion}

Detailed chemical compositions of smoke aerosol from five major agricultural straw burnings were characterized using an aerosol chamber system. The corresponding emission fac- 
tors for particulate OC-EC, WSI, WSOA, WSA, PAHs, phenols, and THM in smoke $\mathrm{PM}_{2.5}$ and $\mathrm{PM}_{1.0}$ were established.

PELs of the smoke particles were assessed for carcinogenic-risk concern based on selected hazard pollutants including PAHs and THM in smoke $\mathrm{PM}_{2.5}$. Daily exposure concentration should be constrained within 0.2 , $0.3,0.4,1.4$, and $0.8 \mu \mathrm{g} \mathrm{m}^{-3}$ for wheat, corn, rice, cotton, and soybean straw, respectively.

Emission inventories of primary particulate pollutants from agricultural field burning in 2012 were estimated based on BAU-I, BAU-II, EM-I, EM-II, and NDRC scenarios, which were further allocated to different regions in the summer and autumn open-burning periods. The estimated total emissions were $1005.7 \mathrm{Gg} \mathrm{PM}_{2.5}$ (95\% CI: -24.6, 33.7\%), 901.4 Gg PM 1.0 (95\% CI: -24.4, $33.5 \%$ ), $432.4 \mathrm{Gg}$ OC $\quad(95 \% \mathrm{CI}: \quad-24.2, \quad 33.5 \%), \quad 134.2 \mathrm{Gg} \mathrm{EC}$ (95\% CI: $-24.8,34.0 \%), 249.8$ Gg WSI (95\% CI: -25.4 , $34.9 \%), \quad 25.1 \mathrm{Gg}$ WSOA $\quad(95 \% \mathrm{CI}:-33.3, \quad 41.4 \%)$, $5.8 \mathrm{Gg}$ WSA $\quad(95 \% \mathrm{CI}: \quad-30.1, \quad 38.5 \%), \quad 8.7 \mathrm{Gg}$ THM (95\% CI: $-26.6,35.6 \%), 0.5 \mathrm{Gg}$ PAHs $(95 \% \mathrm{CI}:-26.0$, $34.9 \%$ ), and $2.7 \mathrm{Gg}$ phenols (95\% CI: $-26.1,35.1 \%$ ). The spatial and temporal distributions of the five versions have similar characteristics that reflect the agricultural fire sites shown by satellite remote sensing. Less than $25 \%$ of the emissions were released from summer field burning and was mainly contributed by the North Plain and the centre of China. Flux concentrations of annual smoke $\mathrm{PM}_{2.5}$ that were calculated using a box-model method based on five versions all exceed the PEL. From the assessment of health impacts and health-related economic losses due to smoke $\mathrm{PM}_{2.5}$ short-term exposure, China suffered from 7836 (95\% CI: $3232,12362)$ cases of premature mortality and 7267237 (95\% CI: 2961487,1130784 ) cases of chronic bronchitis in 2012, which led to losses of USD 8822.4 million (95\% CI: $3574.4,13034.2$ ), or $0.1 \%$ of the total GDP.

The percentage of open-burnt crop straw in the postharvest period should be cut down to less than $3 \%$ to ensure risk aversion from carcinogenicity, especially in the North Plain and the northeast, where the emissions should decrease at least by $94 \%$ to meet the PEL. By applying such an emission control policy, over $92 \%$ of the mortality and morbidity attributed to agricultural fire smoke $\mathrm{PM}_{2.5}$ can be avoided in China.

Data availability. Data are available from the corresponding author on request (jmchen@fudan.edu.cn).

\section{The Supplement related to this article is available online at doi:10.5194/acp-17-4957-2017-supplement.}

Competing interests. The authors declare that they have no conflict of interest.
Acknowledgements. This work is supported by the National Natural Science Foundation of China (no. 21190053, 21177025), the Cyrus Tang Foundation (no. CTF-FD2014001), the Shanghai Science and Technology Commission of Shanghai Municipality (no. 13XD1400700, 12DJ1400100), the Priority fields for PhD Programs Foundation of the Ministry of Education of China (no. 20110071130003) and the Strategic Priority Research Program of the Chinese Academy of Sciences (grant no. XDB05010200).

Edited by: C. K. Chan

Reviewed by: two anonymous referees

\section{References}

Ackerman, A. S.: Reduction of Tropical Cloudiness by Soot, Science, 5468, 1042-1047, 2000.

Adams, P. J., Seinfeld, J. H., and Koch, D. M.: Global concentrations of tropospheric sulfate, nitrate, and ammonium aerosol simulated in a general circulation model, J. Geophys. Res., 104, 13791-13823, 1999.

Akagi, S. K., Yokelson, R. J., Wiedinmyer, C., Alvarado, M. J., Reid, J. S., Karl, T., Crounse, J. D., and Wennberg, P. O.: Emission factors for open and domestic biomass burning for use in atmospheric models, Atmos. Chem. Phys., 11, 4039-4072, doi:10.5194/acp-11-4039-2011, 2011.

Amdur, M. O. and Chen, L. C.: Furnace-Generated Acid Aerosols: Speciation and Pulmonary Effects, Environ. Health Persp., 79, 147-150, 1989.

Andreae, M. O. and Gelencsér, A.: Black carbon or brown carbon? The nature of light-absorbing carbonaceous aerosols, Atmos. Chem. Phys., 6, 3131-3148, doi:10.5194/acp-6-3131-2006, 2006.

Andreae, M. O. and Merlet, P.: Emission of trace gases and aerosols from biomass burning, Global Biogeochem. Cy., 4, 955-966, 2001.

Andreae, M. O., Andreae, T. W., Annegarn, H., Beer, J., Cachier, H., le Canut, P., Elbert, W., Maenhaut, W., Salma, I., Wienhold, F. G., and Zenke, T.: Airborne studies of aerosol emissions from savanna fires in southern Africa: 2. Aerosol chemical composition, J. Geophys. Res., 103, 32119-32128, 1998.

Araujo, J. A., Barajas, B., Kleinman, M., Wang, X., Bennett, B. J., Gong, K. W., Navab, M., Harkema, J., Sioutas, C., Lusis, A J., and Nel, A. E.: Ambient particulate pollutants in the ultrafine range promote early atherosclerosis and systemic oxidative stress, Circ Res., 5, 589-596, 2008.

Arey, J. and Atkinson, R.: Photochemical reactions of PAHs in the atmosphere, In: PAHs: An Ecotoxicological Persp., edited by: Douben, P. E. T., John Wiley \& Sons, Ltd., Chichester, UK, 47 63, doi:10.1002/0470867132.ch4, 2003.

Arora, P. and Jain, S.: Estimation of Organic and Elemental Carbon Emitted from Wood Burning in Traditional and Improved Cookstoves Using Controlled Cooking Test, Environ. Sci. Technol., 6, 3958-3965, 2015.

Aunan, K. and Pan, X.: Exposure-response functions for health effects of ambient air pollution applicable for China-a metaanalysis, Sci. Total Environ., 329, 3-16, 2004.

Aurell, J., Gullett, B. K., and Tabor, D.: Emissions from southeastern U.S. Grasslands and pine savannas: Comparison of aerial and 
ground field measurements with laboratory burns, Atmos. Environ., 111, 170-178, 2015.

Bell, R. W. and Hipfner, J. C.: Airborne Hexavalent Chromium in Southwestern Ontario, J. Air Waste Manage., 8, 905-910, 1997.

Berndt, T. and Böge, O.: Formation of phenol and carbonyls from the atmospheric reaction of $\mathrm{OH}$ radicals with benzene, Phys. Chem. Chem. Phys., 10, 1205-1214, doi:10.1039/B514148F, 2006.

Bølling, A. K., Pagels, J., Yttri, K. E., Barregard, L., Sallsten, G., Schwarze, P. E., and Boman, C.: Health effects of residential wood smoke particles: the importance of combustion conditions and physicochemical particle properties, Part. Fibre Toxicol., 29, doi:10.1186/1743-8977-6-29, 2009.

Bond, T. C.: A technology-based global inventory of black and organic carbon emissions from combustion, J. Geophys. Res., 109, D14203, doi:10.1029/2003JD003697, 2004.

Bond, T. C., Doherty, S. J., Fahey, D. W., Forster, P. M., Berntsen, T., DeAngelo, B. J. Flanner, M. G., Ghan, S., Kärcher, B., Koch, D., Kinne, S., Kondo, Y., Quinn, P. K., Sarofim, M. C., Schultz, M. G., Schulz, M., Venkataraman, C., Zhang, H., Zhang, S., Bellouin, N., Guttikunda, S. K., Hopke, P. K., Jacobson, M. Z., Kaiser, J. W., Klimont, Z., Lohmann, U., Schwarz, J., PShindell, D., Storelvmo, T., Warren, S. G., and Zender, C. S.: Bounding the role of black carbon in the climate system: A scientific assessment, J. Geophys. Res.-Atmos., 11, 5380-5552, 2013.

Bruce, R. M., Santodonato, J., and Neal, M. W.: Summary Review of the Health Effects Associated With Phenol, Toxicol Ind. Health, 4, 535-568, 1987.

Buha, J., Mueller, N., Nowack, B., Ulrich, A., Losert, S., and Wang, J.: Physical and Chemical Characterization of Fly Ashes from Swiss Waste Incineration Plants and Determination of the Ash Fraction in the Nanometer Range, Environ. Sci. Technol., 9, 4765-4773, 2014.

Burkart, K., Nehls, I., Win, T., and Endlicher, W.: The carcinogenic risk and variability of particulate-bound polycyclic aromatic hydrocarbons with consideration of meteorological conditions, Air Quality, Atmos. Health, 1, 27-38, 2013.

Bzdek, B. R., Ridge, D. P., and Johnston, M. V.: Amine exchange into ammonium bisulfate and ammonium nitrate nuclei, Atmos. Chem. Phys., 10, 3495-3503, doi:10.5194/acp-10-3495-2010, 2010.

Bzdek, B. R., Ridge, D. P., and Johnston, M. V.: Amine reactivity with charged sulfuric acid clusters, Atmos. Chem. Phys., 11, 8735-8743, doi:10.5194/acp-11-8735-2011, 2011.

Cao, G., Zhang, X., Wang, D., and Zheng, F.: Inventory of Emissions of Pollutants from Open Burning Crop Residues, J. AgroEnviron. Sci., 4, 800-804, 2005.

Cao, G., Zhang, X., and Zheng, F.: Inventory of black carbon and organic carbon emissions from China, Atmos. Environ., 34, 65166527, 2006.

Cao, G., Zhang, X., Gong, S., An, X., and Wang, Y.: Emission inventories of primary particles and pollutant gases for China, Chinese Sci. Bull, 8, 781-788, 2011.

Cao, J., Xu, H., Xu, Q., Chen, B., and Kan, H.: Fine particulate matter constituents and cardiopulmonary mortality in a heavily polluted Chinese city, Environ. Health Persp., 120, 373-378, 2012.

Carlton, A. G., Turpin, B. J., Lim, H., Altieri, K. E., and Seitzinger, S.: Link between isoprene and secondary organic aerosol (SOA): Pyruvic acid oxidation yields low volatility organic acids in clouds, Geophys. Res. Lett., 33, L06822, doi:10.1029/2005GL025374, 2006.

Cermak, J. and Knutti, R.: Beijing Olympics as an aerosol field experiment, Geophys. Res. Lett., 36, L10806, doi:10.1029/2009GL038572, 2009.

Chakrabarty, R. K., Moosmüller, H., Chen, L.-W. A., Lewis, K., Arnott, W. P., Mazzoleni, C., Dubey, M. K., Wold, C. E., Hao, W. M., and Kreidenweis, S. M.: Brown carbon in tar balls from smoldering biomass combustion, Atmos. Chem. Phys., 10, 63636370, doi:10.5194/acp-10-6363-2010, 2010.

Chan, M. N., Choi, M. Y., Ng, N. L., and Chan, C. K.: Hygroscopicity of Water-Soluble Organic Compounds in Atmospheric Aerosols: Amino Acids and Biomass Burning Derived Organic Species, Environ. Sci. Technol., 6, 1555-1562, 2005.

Chen, H., Hu, D., Wang, L., Mellouki, A., and Chen, J.: Modification in light absorption cross section of laboratory-generated black carbon-brown carbon particles upon surface reaction and hydration, Atmos. Environ., 116, 253-261, 2015.

Chen, R., Li, Y., Ma, Y., Pan, G., Zeng, G., Xu, X., Chen, B., and Kan, H.: Coarse particles and mortality in three Chinese cities: The China Air Pollution and Health Effects Study (CAPES), Sci. Total Environ., 23, 4934-4938, 2011.

Cheng, Y., Ho, K. F., Lee, S. C., and Law, S. W.: Seasonal and diurnal variations of $\mathrm{PM}_{1.0}, \mathrm{PM}_{2.5}$ and $\mathrm{PM}_{10}$ in the roadside environment of Hong Kong, China Particuol., 06, 312-315, 2006.

Christopher, S. A., Chou, J., Zhang, J., Li, X., Berendes, T., and Welch, R. M.: Shortwave direct radiative forcing of biomass burning aerosols estimated using VIRS and CERES data, Geophys. Res. Lett., 15, 2197-2200, 2000.

Clarke, A., McNaughton, C., Kapustin, V., Shinozuka, Y., Howell, S., Dibb, J., Zhou, J., Anderson, B., Brekhovskikh, V., Turner, H., and Pinkerton, M.: Biomass burning and pollution aerosol over North America: Organic components and their influence on spectral optical properties and humidification response, J. Geophys. Res., 112, D12S18, doi:10.1029/2006JD007777, 2007.

$\mathrm{CMH}$ - China Ministry of Health: China statistical yearbook of public health, Peking Union Medical College Press, Peking, 172189, 2009.

Cwiertny, D. M., Baltrusaitis, J., Hunter, G. J., Laskin, A., Scherer, M. M., and Grassian, V. H.: Characterization and acid-mobilization study of iron-containing mineral dust source materials, J. Geophys. Res.-Atmos., 113, D05202, doi:10.1029/2007JD009332, 2008.

Daize, H.: The Utilizing Status and Prospects of the Crop Straw Resources in China, Resour. Dev. Market, 3, 01, 2000.

Davidson, C. I., Phalen, R. F., and Solomon, P. A.: Airborne Particulate Matter and Human Health: A Review, Aerosol Sci. Tech. 8, 737-749, 2005.

Delfino, R. J., Sioutas, C., and Malik, S.: Potential role of ultrafine particles in associations between airborne particle mass and cardiovascular health, Environ. Health Persp., 8, 934-946, 2005.

Dentener, F. J., Carmichael, G. R., Zhang, Y., Lelieveld, J., and Crutzen, P. J.: Role of mineral aerosol as a reactive surface in the global troposphere, J. Geophys. Res., 101, 22869-22889, doi:10.1029/96JD01818, 1996.

Dhammapala, R., Claiborn, C., Corkill, J., and Gullett, B.: Particulate emissions from wheat and Kentucky bluegrass stubble burning in eastern Washington and northern Idaho, Atmos. Environ., 6, 1007-1015, 2006. 
Dhammapala, R., Claiborn, C., Jimenez, J., Corkill, J., Gullett, B., Simpson, C., and Paulsen, M.: Emission factors of PAHs, methoxyphenols, levoglucosan, elemental carbon and organic carbon from simulated wheat and Kentucky bluegrass stubble burns, Atmos. Environ., 12, 2660-2669, 2007a.

Dhammapala, R., Claiborn, C., Simpson, C., and Jimenez, J.: Emission factors from wheat and Kentucky bluegrass stubble burning: Comparison of field and simulated burn experiments, Atmos. Environ., 7, 1512-1520, 2007b.

Dusek, U., Frank, G. P., Hildebrandt, L., Curtius, J., Schneider, J., Walter, S., Chand, D., Drewnick, F., Hings, S., and Jung, D.: Size matters more than chemistry for cloud-nucleating ability of aerosol particles, Science, 5778, 1375-1378, 2006.

Echalar, F., Gaudichet, A., Cachier, H., and Artaxo, P.: Aerosol emissions by tropical forest and savanna biomass burning: Characteristic trace elements and fluxes, Geophys. Res. Lett., 22, 3039-3042, doi:10.1029/95GL03170, 1995.

Engelhart, G. J., Hennigan, C. J., Miracolo, M. A., Robinson, A. L., and Pandis, S. N.: Cloud condensation nuclei activity of fresh primary and aged biomass burning aerosol, Atmos. Chem. Phys., 15, 7285-7293, doi:10.5194/acp-12-7285-2012, 2012.

Falkovich, A. H., Graber, E. R., Schkolnik, G., Rudich, Y., Maenhaut, W., and Artaxo, P.: Low molecular weight organic acids in aerosol particles from Rondônia, Brazil, during the biomassburning, transition and wet periods, Atmos. Chem. Phys., 5, 781797, doi:10.5194/acp-5-781-2005, 2005.

Frey, H. C. and Zhao, Y.: Quantification of Variability and Uncertainty for Air Toxic Emission Inventories with Censored Emission Factor Data, Environ. Sci. Technol., 22, 6094-6100, 2004.

Frey, H. C. and Zheng, J.: Quantification of variability and uncertainty in air pollutant emission inventories: method and case study for utility $\mathrm{NO}_{x}$ emissions, J. Air Waste Manage. Assoc., 9, 1083-1095, 2002.

Fu, H., Zhang, M., Li, W., Chen, J., Wang, L., Quan, X., and Wang, W.: Morphology, composition and mixing state of individual carbonaceous aerosol in urban Shanghai, Atmos. Chem. Phys., 12, 693-707, doi:10.5194/acp-12-693-2012, 2012.

Galarneau, E.: Source specificity and atmospheric processing of airborne PAHs: Implications for source apportionment, Atmos. Environ., 35, 8139-8149, 2008.

Gao, M., Guttikunda, S. K., Carmichael, G. R., Wang, Y., Liu, Z., Stanier, C. O., Saide, P. E., and Yu, M.: Health impacts and economic losses assessment of the 2013 severe haze event in Beijing area, Sci. Total Environ., 511, 553-561, 2015.

Gao, S., Hegg, D. A., Hobbs, P. V., Kirchstetter, T. W., Magi, B. I., and Sadilek, M.: Water-soluble organic components in aerosols associated with savanna fires in southern Africa: Identification, evolution, and distribution, J. Geophys. Res.-Atmos., 108, 8491, doi:10.1029/2002JD002324, 2003.

Ge, X., Wexler, A. S., and Clegg, S. L.: Atmospheric aminesPart I. A review, Atmos. Environ., 3, 524-546, 2011.

Ghorai, S., Wang, B., Tivanski, A., and Laskin, A.: Hygroscopic Properties of Internally Mixed Particles Composed of $\mathrm{NaCl}$ and Water-Soluble Organic Acids, Environ. Sci. Technol., 48, 2234 2241, doi:10.1021/es404727u, 2014.

Giordano, M., Espinoza, C., and Asa-Awuku, A.: Experimentally measured morphology of biomass burning aerosol and its impacts on CCN ability, Atmos. Chem. Phys., 15, 1807-1821, doi:10.5194/acp-15-1807-2015, 2015.
Grieshop, A. P., Logue, J. M., Donahue, N. M., and Robinson, A. L.: Laboratory investigation of photochemical oxidation of organic aerosol from wood fires 1: measurement and simulation of organic aerosol evolution, Atmos. Chem. Phys., 9, 1263-1277, doi:10.5194/acp-9-1263-2009, 2009.

Guttikunda, S. K. and Kopakka, R. V.: Source emissions and health impacts of urban air pollution in Hyderabad, India, Air Qual. Atmos. Health, 2, 195-207, 2014.

Han, Y. M., Cao, J., Chow, J. C., Watson, J. G., An, Z., Jin, Z., Fung, K., and Liu, S.: Evaluation of the thermal/optical reflectance method for discrimination between char- and soot-EC, Chemosphere, 4, 569-574, 2007.

Han, Y. M., Lee, S. C., Cao, J. J., Ho, K. F., and An, Z. S.: Spatial distribution and seasonal variation of char-EC and soot-EC in the atmosphere over China, Atmos. Environ., 38, 6066-6073, 2009.

Han, Y. M., Chen, L., Huang, R., Chow, J. C., Watson, J. G., Ni, H. Y., Liu, S. X., Fung, K. K., Shen, Z. X., and Wei, C.: Carbonaceous aerosols in megacity Xi'an, China: Implications of thermal/optical protocols comparison, Atmos. Environ., 132, 58-68, 2016.

Hayashi, K., Ono, K., Kajiura, M., Sudo, S., Yonemura, S., Fushimi, A., Saitoh, K., Fujitani, Y., and Tanabe, K.: Trace gas and particle emissions from open burning of three cereal crop residues: Increase in residue moistness enhances emissions of carbon monoxide, methane, and particulate organic carbon, Atmos. Environ., 95, 36-44, 2014.

Hays, M. D., Fine, P. M., Geron, C. D., Kleeman, M. J., and Gullett, B. K.: Open burning of agricultural biomass: physical and chemical properties of particle-phase emissions, Atmos. Environ., 36, 6747-6764, 2005.

He, K., Zhao, Q., Ma, Y., Duan, F., Yang, F., Shi, Z., and Chen, G.: Spatial and seasonal variability of $\mathrm{PM}_{2.5}$ acidity at two Chinese megacities: insights into the formation of secondary inorganic aerosols, Atmos. Chem. Phys., 12, 1377-1395, doi:10.5194/acp12-1377-2012, 2012.

He, M., Zheng, J., Yin, S. and Zhang, Y.: Trends, temporal and spatial characteristics, and uncertainties in biomass burning emissions in the Pearl River Delta, China, Atmos. Environ., 24, 40514059, 2011.

Ho, K. F., Ho, S. S. H., Huang, R., Liu, S. X., Cao, J., Zhang, T., Chuang, H., Chan, C. S., Hu, D., and Tian, L.: Characteristics of water-soluble organic nitrogen in fine particulate matter in the continental area of China, Atmos. Environ., 106, 252-261, 2015.

Hou, Q., An, X., Wang, Y., Tao, Y., and Sun, Z.: An assessment of China's $\mathrm{PM}_{10}$-related health economic losses in 2009, Sci. Total. Environ., 435-436, 61-65, 2012.

Hu, Y., Lin, J., Zhang, S., Kong, L., Fu, H., and Chen, J.: Identification of the typical metal particles among haze, fog, and clear episodes in the Beijing atmosphere, Sci. Total Environ., 511, 369-380, 2015.

Huang, K., Zhuang, G., Lin, Y., Fu, J. S., Wang, Q., Liu, T., Zhang, R., Jiang, Y., Deng, C., Fu, Q., Hsu, N. C., and Cao, B.: Typical types and formation mechanisms of haze in an Eastern Asia megacity, Shanghai, Atmos. Chem. Phys., 12, 105-124, doi:10.5194/acp-12-105-2012, 2012.

Huang, K., Zhuang, G., Lin, Y., Wang, Q., Fu, J. S., Fu, Q., Liu, T., and Deng, C.: How to improve the air quality over megacities in China: pollution characterization and source analysis in Shang- 
hai before, during, and after the 2010 World Expo, Atmos. Chem. Phys., 13, 5927-5942, doi:10.5194/acp-13-5927-2013, 2013.

Huang, R., Zhang, Y., Bozzetti, C., Ho, K., Cao, J., Han, Y., Daellenbach, K. R.,Slowik, J. G., Platt, S. M., Canonaco, F., Zotter, P., Wolf, R., Pieber, S., Bruns, E., Crippa, M., Ciarelli, G., Piazzalunga, A., Schnelle-Kreis, J., Zimmermann, R., An, Z., Szidat, S., Baltensperger, U., Haddad, I., and Prevot, A.: High secondary aerosol contribution to particulate pollution during haze events in China, Nature, 514, 218-222, doi:10.1038/nature13774, 2014.

Huang, S., Hsu, M., and Chan, C.: Effects of submicrometer particle compositions on cytokine production and lipid peroxidation of human bronchial epithelial cells., Environ. Health Persp., 111, 478-482, 2003.

Huang, X., Li, M., Li, J., and Song, Y.: A high-resolution emission inventory of crop burning in fields in China based on MODIS Thermal Anomalies/Fire products, Atmos. Environ., 50, 9-15, 2012

Huo, J., Lu, X., Wang, X., Chen, H., Ye, X., Gao, S., Gross, D. S., Chen, J., and Yang, X.: Online single particle analysis of chemical composition and mixing state of crop straw burning particles: from laboratory study to field measurement, Front Environ. Sci. Eng., 2, 244-252, 2016.

IBRD and SEPA: Cost of pollution in China: economic estimates of physical damages, in: conference edition of Environmental and Social development unit, East Asia \& Pacific Region, 1-128, available at: http://www.worldbank.org/eapenvment (last access: April 2017), 2007.

IPCC: Quantifying Uncertainties in Practice, in: chap. 6: Good Practice Guidance and Uncertainty Management in National Greenhouse Gas Inventories, IES, IPCC, OECD, Bracknell, UK, 1997.

IPCC: Greenhouse Gas Inventory Reference Manual: Revised 2006 IPCC Guidelines for National Greenhouse Gas Inventories, IPCC/OECD/IES, UK, Meteorological Office, Bracknell, UK, 2007.

Janssen, N. A. H., Hoek, G., Simic-Lawson, M., Fischer, P., van Bree, L., Ten Brink, H., Keuken, M., Atkinson, R., Anderson, H., Brunekreef, B., and Cassee, F.: Black Carbon as an Additional Indicator of the Adverse Health Effects of Airborne Particles Compared with $\mathrm{PM}_{10}$ and $\mathrm{PM}_{2.5}$, Environ. Health Persp., 12, 1691-1699, 2011.

Jayarathne, T., Stockwell, C. E., Yokelson, R. J., Nakao, S., and Stone, E. A.: Emissions of fine particle fluoride from biomass burning, Environ. Sci. Technol., 21, 12636-12644, 2014

Jenkins, B. M., Jones, A. D., Turn, S. Q., and Williams, R. B.: Emission factors for polycyclic aromatic hydrocarbons from biomass burning, Environ. Sci. Technol., 8, 2462-2469, 1996.

Jickells, T. D., An, Z. S., Andersen, K. K., Baker, A. R., Bergametti, G., J, N. B. J., Duce, R. A., Hunter, H., Mahowald, N., and Prospero, A.: Global Iron Connections Between Desert Dust, Ocean Biogeochemistry, and Climate, Science, 308, 67-71, 2005.

Kennedy, I. M.: The health effects of combustion-generated aerosols, P. Combust. Inst., 2, 2757-2770, 2007.

Kim, K., Jahan, S. A., Kabir, E., and Brown, R. J.: A review of airborne polycyclic aromatic hydrocarbons (PAHs) and their human health effects, Environ. Int., 60, 71-80, 2013.

Kong, L., Yang, Y., Zhang, S., Zhao, X., Du, H., Fu, H., Zhang, S., Cheng, T., Yang, X., and Chen, J.: Observations of linear dependence between sulfate and nitrate in atmospheric particles, J.
Geophys. Res.-Atmos., 1, 341-361, doi:10.1002/2013JD020222, 2014.

Koopmans, A. and Koppejan, J.: Agricultural and forest residuegeneration, utilization and availability, Modern Applications of Biomass Energy, the paper is presented at the regional consultation on Modern Application of Biomass Energy, 610 January 1997, available at: http://www.wgbis.ces.iisc.ernet.in/ energy/HC20799/RWEDP/acrobat/p_residues.pdf (last access: April 2017), 1997.

Korenaga, T., Liu, X., and Huang, Z.: The influence of moisture content on polycyclic aromatic hydrocarbons emission during rice straw burning, Chemosphere, 1, 117-122, 2001

Kundu, S., Kawamura, K., Andreae, T. W., Hoffer, A., and Andreae, M. O.: Molecular distributions of dicarboxylic acids, ketocarboxylic acids and $\alpha$-dicarbonyls in biomass burning aerosols: implications for photochemical production and degradation in smoke layers, Atmos. Chem. Phys., 10, 2209-2225, doi:10.5194/acp-10-2209-2010, 2010.

Laskin, A., Laskin, J., and Nizkorodov, S. A.: Chemistry of atmospheric brown carbon, Chem. Rev., 10, 4335-4382, 2015.

Lavanchy, V. M. H., Ggeler, H. W., Nyeki, S., and Baltensperger, U.: Elemental carbon (EC) and black carbon (BC) measurements with a thermal method and an aethalometer at the high-alpine research station Jungfraujoch, Atmos. Environ., 17, 2759-2769, 1999.

Lee, A. K. Y., Willis, M. D., Healy, R. M., Wang, J. M., Jeong, C.-H., Wenger, J. C., Evans, G. J., and Abbatt, J. P. D.: Single-particle characterization of biomass burning organic aerosol (BBOA): evidence for non-uniform mixing of high molecular weight organics and potassium, Atmos. Chem. Phys., 16, 5561-5572, doi:10.5194/acp-16-5561-2016, 2016.

Lee, D. and Wexler, A. S.: Atmospheric amines - Part III: Photochemistry and toxicity, Atmos. Environ., 71, 95-103, 2013.

Lee, R. G. M., Coleman, P., Jones, J. L., Jones, K. C., and Lohmann, R.: Emission Factors and Importance of PCDD/Fs, PCBs, PCNs, PAHs and $\mathrm{PM}_{10}$ from the Domestic Burning of Coal and Wood in the U.K., Environ. Sci. Technol., 6, 1436-1447, 2005.

Leng, C., Zhang, Q., Zhang, D., Xu, C., Cheng, T., Zhang, R., Tao, J., Chen, J., Zha, S., and Zhang, Y.: Variations of cloud condensation nuclei $(\mathrm{CCN})$ and aerosol activity during fog-haze episode: a case study from Shanghai, Atmos. Chem. Phys., 22, 1249912512, doi:10.5194/acp-14-12499-2014, 2014.

Levin, E. J. T., McMeeking, G. R., Carrico, C. M., Mack, L. E., Kreidenweis, S. M., Wold, C. E., Moosmüller, H., Arnott, W., Hao, W., Collett, J., and Malm, W.: Biomass burning smoke aerosol properties measured during Fire Laboratory at Missoula Experiments (FLAME), J. Geophys. Res., 115, D18210, doi:10.1029/2009JD013601, 2010.

Lewis, K. A., Arnott, W. P., Moosmüller, H., Chakrabarty, R. K., Carrico, C. M., Kreidenweis, S. M., Day, D. E., Malm, W. C., Laskin, A., Jimenez, J. L., Ulbrich, I. M., Huffman, J. A., Onasch, T. B., Trimborn, A., Liu, L., and Mishchenko, M. I.: Reduction in biomass burning aerosol light absorption upon humidification: roles of inorganically-induced hygroscopicity, particle collapse, and photoacoustic heat and mass transfer, Atmos. Chem. Phys., 9, 8949-8966, doi:10.5194/acp-9-8949-2009, 2009.

Li, C., Ma, Z., Chen, J., Wang, X., Ye, X., Wang, L., Yang, X., Kan, H., Donaldson, D., and Mellouki, A.: Evolution of biomass 
burning smoke particles in the dark, Atmos. Environ., 120, 244 252, 2015.

Li, C., Hu, Y., Chen, J., Ma, Z., Ye, X., Yang, X., Wang, L., Wang, X., and Mellouki, A.: Physiochemical properties of carbonaceous aerosol from agricultural residue burning: Density, volatility, and hygroscopicity, Atmos. Environ., 140, 94-105, doi:10.1016/j.atmosenv.2016.05.052, 2016.

Li, J., Pósfai, M., Hobbs, P. V., and Buseck, P. R.: Individual aerosol particles from biomass burning in southern Africa: 2, Compositions and aging of inorganic particles, J. Geophys. Res.-Atmos., 108, 8484, doi:10.1029/2002JD002310, 2003.

Li, X., Wang, S., Duan, L., Hao, J., Li, C., Chen, Y., and Yang, L.: Particulate and trace gas emissions from open burning of wheat straw and corn stover in China, Environ. Sci. Technol., 17, 60526058, 2007.

Lima, A. L. C., Farrington, J. W., and Reddy, C. M.: CombustionDerived Polycyclic Aromatic Hydrocarbons in the Environment - A Review, Environ. Forensics, 2, 109-131, 2005.

Lin, J., Nielsen, C. P., Zhao, Y., Lei, Y., Liu, Y., and McElroy, M. B.: Recent changes in particulate air pollution over China observed from space and the ground: effectiveness of emission control, Environ. Sci. Technol., 20, 7771-7776, 2010.

Lin, P., Aiona, P. K., Li, Y., Shiraiwa, M., Laskin, J., Nizkorodov, S. A., and Laskin, A.: Molecular Characterization of Brown Carbon in Biomass Burning Aerosol Particles, Environ. Sci. Technol., 21, 11815-11824, 2016.

Liu, M., Song, Y., Yao, H., Kang, Y., Li, M., Huang, X., and Hu, M.: Estimating emissions from agricultural fires in the North China Plain based on MODIS fire radiative power, Atmos. Environ., 112, 326-334, 2015.

Liu, Q. and Bei, Y.: Impacts of crystal metal on secondary aliphatic amine aerosol formation during dust storm episodes in Beijing, Atmos. Environ., 128, 227-234, 2016.

Lobert, J. M., Scharffe, D. H., Hao, W. M., and Crutzen, P. J.: Importance of biomass burning in the atmospheric budgets of nitrogencontaining gases, Nature, 346, 552-554, 1990.

Lu, Z., Zhang, Q., and Streets, D. G.: Sulfur dioxide and primary carbonaceous aerosol emissions in China and India, 1996-2010, Atmos. Chem. Phys., 11, 9839-9864, doi:10.5194/acp-11-98392011, 2011.

Ma, J. and van Aardenne, J. A.: Impact of different emission inventories on simulated tropospheric ozone over China: a regional chemical transport model evaluation, Atmos. Chem. Phys., 4, 877-887, doi:10.5194/acp-4-877-2004, 2004.

May, A. A., McMeeking, G. R., Lee, T., Taylor, J. W., Craven, J. S., Burling, I., Sullivan, A. P., Akagi, S., Collett, J., Flynn, M., Coe, H., Urbanski, S., Seinfeld, J., Yokelson, R., and Kreidenweis, S.: Aerosol emissions from prescribed fires in the United States: A synthesis of laboratory and aircraft measurements, J. Geophys. Res.-Atmos., 20, 11826-11849, doi:10.1002/2014JD021848, 2014.

Meskhidze, N.: Dust and pollution: A recipe for enhanced ocean fertilization?, J. Geophys. Res., 110, D03301, doi:10.1029/2004JD005082, 2005.

Mikhailov, E. F., Vlasenko, S. S., Podgorny, I. A., Ramanathan, V., and Corrigan, C. E.: Optical properties of soot-water drop agglomerates: An experimental study, J. Geophys. Res., 111, D07209, doi:10.1029/2005JD006389, 2006.
Moreno, T., Karanasiou, A., Amato, F., Lucarelli, F., Nava, S., Calzolai, G., Chiari, M., Coz, E., Artinano, B., Lumbreras, J., Borge, R., Boldo, R., Linares, C., Alastursy, A., Querol, X., and Gibbons, X.: Daily and hourly sourcing of metallic and mineral dust in urban air contaminated by traffic and coal-burning emissions, Atmos. Environ., 68, 33-44, 2013.

NBSC: China Statistical Yearbook 2013, China Statistics Press, Beijing, China, 2013.

NBSC - National Bureau of Statistics of China: China Statistical Yearbook (2004-2013), China Statistics Press, Beijing, China, 2004-2013.

NDRC - National Development and Reform Commission of China: Report on national crop residues utilization and field burning condition, No. 516, available at: http://www.ndrc.gov.cn/ zcfb/zcfbtz/201403/w020140317384287461932.pdf (last access: April 2017), 2014.

NHFPC: National Health and Family Planning Yearbook, Peking Union Medical College Press, Beijing, p. 415, 2013.

Oanh, N. T. K., Ly, B. T., Tipayarom, D., Manandhar, B. R., Prapat, P., Simpson, C. D., and Liu, L. S.: Characterization of particulate matter emission from open burning of rice straw, Atmos. Environ., 2, 493-502, 2011.

Ostro, B. and Chestnut, L.: Assessing the health benefits of reducing particulate matter air pollution in the United States, Environ. Res., 2, 94-106, 1998.

Pope III, C. A., Burnett, R. T., Thun, M. J., Calle, E. E., Krewski, D., Ito, K., and Thurston, G. D.: Lung cancer, cardiopulmonary mortality, and long-term exposure to fine particulate air pollution, the paper is presented at the JAMA network, American Medical Association, 1132-1141, available at: http://www.jamanetwork. com/journals/jama/fullarticle/197704 (last access: April 2017), 2002.

Pope, C. A., Burnett, R. T., Thurston, G. D., Thun, M. J., Calle, E. E., Krewski, D., and Godleski, J. J.: Cardiovascular mortality and long-term exposure to particulate air pollution epidemiological evidence of general pathophysiological pathways of disease, Circulation, 1, 71-77, 2004.

Pósfai, M.: Atmospheric tar balls: Particles from biomass and biofuel burning, J. Geophys. Res., 109, D06213, doi:10.1029/2003JD004169, 2004.

Qin, Y. and Xie, S. D.: Historical estimation of carbonaceous aerosol emissions from biomass open burning in China for the period 1990-2005, Environ Pollut., 12, 3316-3323, 2011.

Qin, Y. and Xie, S. D.: Spatial and temporal variation of anthropogenic black carbon emissions in China for the period 19802009, Atmos. Chem. Phys., 12, 4825-4841, doi:10.5194/acp-124825-2012, 2012.

Qiu, C. and Zhang, R.: Physiochemical Properties of Alkylaminium Sulfates: Hygroscopicity, Thermostability, and Density, Environ. Sci. Technol., 8, 4474-4480, 2012.

Qiu, C., Wang, L., Lal, V., Khalizov, A. F., and Zhang, R.: Heterogeneous Reactions of Alkylamines with Ammonium Sulfate and Ammonium Bisulfate, Environ. Sci. Technol., 11, 4748-4755, 2011.

Ram, K. and Sarin, M. M.: Day-night variability of EC, OC, WSOC and inorganic ions in urban environment of Indo-Gangetic Plain: implications to secondary aerosol formation, Atmos. Environ., 2, 460-468, 2011. 
Ram, K., Sarin, M. M., and Tripathi, S. N.: Temporal Trends in Atmospheric $\mathrm{PM}_{2.5}, \mathrm{PM}_{10}$, Elemental Carbon, Organic Carbon, Water-Soluble Organic Carbon, and Optical Properties: Impact of Biomass Burning Emissions in The Indo-Gangetic Plain, Environ. Sci. Technol., 2, 686-695, 2011.

Reddy, M. S. and Venkataraman, C.: Atmospheric optical and radiative effects of anthropogenic aerosol constituents from India, Atmos. Environ., 34, 4511-4523, 2000.

Reid, J. S., Eck, T. F., Christopher, S. A., Koppmann, R., Dubovik, O., Eleuterio, D. P., Holben, B. N., Reid, E. A., and Zhang, J.: A review of biomass burning emissions part III: intensive optical properties of biomass burning particles, Atmos. Chem. Phys., 5, 827-849, doi:10.5194/acp-5-827-2005, 2005a.

Reid, J. S., Koppmann, R., Eck, T. F., and Eleuterio, D. P.: A review of biomass burning emissions part II: intensive physical properties of biomass burning particles, Atmos. Chem. Phys., 5, 799825, doi:10.5194/acp-5-799-2005, 2005 b.

Richter, H. and Howard J. B.: Formation of polycyclic aromatic hydrocarbons and their growth to soot-a review of chemical reaction pathways, Prog. Energy Combust., 4, 565-608, 2000.

Ripoll, A., Minguillón, M. C., Pey, J., Pérez, N., Querol, X., and Alastuey, A.: Joint analysis of continental and regional background environments in the western Mediterranean: $\mathrm{PM}_{1}$ and $\mathrm{PM}_{10}$ concentrations and composition, Atmos. Chem. Phys., 2, 1129-1145, doi:10.5194/acp-15-1129-2015, 2015.

Roemer, W. H. and van Wijnen, J. H.: Differences among Black Smoke, $\mathrm{PM}_{10}$, and $\mathrm{PM}_{1.0}$ Levels at Urban Measurement Sites, Environ. Health Persp., 2, 151-153, 2001.

Rose, D., Gunthe, S. S., Su, H., Garland, R. M., Yang, H., Berghof, M., Cheng, Y. F., Wehner, B., Achtert, P., Nowak, A., Wiedensohler, A., Takegawa, N., Kondo, Y., Hu, M., Zhang, Y., Andreae, M., and Pöschl, U.: Cloud condensation nuclei in polluted air and biomass burning smoke near the mega-city Guangzhou, China - Part 2: Size-resolved aerosol chemical composition, diurnal cycles, and externally mixed weakly $\mathrm{CCN}$-active soot particles, Atmos. Chem. Phys., 6, 2817-2836, doi:10.5194/acp-112817-2011, 2011.

Rosenfeld, D.: Atmosphere: Aerosols, Clouds, and Climate, Science, 5778, 1323-1324, 2006.

Safai, P. D., Raju, M. P., Budhavant, K. B., Rao, P., and Devara, P.: Long term studies on characteristics of black carbon aerosols over a tropical urban station Pune, India, Atmos. Res., 132-133, 173-184, 2013.

Saffari, A., Daher, N., Samara, C., Voutsa, D., Kouras, A., Manoli, E., Karagkiozidou, O., Vlachokostas, C., Moussiopoulos, N., Shafer, M., Schauer, J., and Sioutas, C.: Increased Biomass Burning Due to the Economic Crisis in Greece and Its Adverse Impact on Wintertime Air Quality in Thessaloniki, Environ. Sci. Technol., 23, 13313-13320, 2013.

Saikawa, E., Naik, V., Horowitz, L. W., Liu, J., and Mauzerall, D. L.: Present and potential future contributions of sulfate, black and organic carbon aerosols from China to global air quality, premature mortality and radiative forcing, Atmos. Environ., 17, 2814 2822, 2009.

Samy, S. and Hays, M. D.: Quantitative LC-MS for water-soluble heterocyclic amines in fine aerosols $\left(\mathrm{PM}_{2.5}\right)$ at Duke Forest, USA, Atmos. Environ., 72, 77-80, 2013.
Santodonato, J.: Review of the estrogenic and antiestrogenic activity of polycyclic aromatic hydrocarbons: relationship to carcinogenicity, Chemosphere, 4, 835-848, 1997.

Schade, G. W. and Crutzen, P. J.: Emission of aliphatic amines from animal husbandry and their reactions: Potential source of $\mathrm{N}_{2} \mathrm{O}$ and HCN, J. Atmos. Chem., 3, 319-346, 1995.

Schauer, J. J., Kleeman, M. J., Cass, G. R., and Simoneit, B. R. T.: Measurement of Emissions from Air Pollution Sources. 3. $\mathrm{C}_{1}-$ $\mathrm{C}_{29}$ Organic Compounds from Fireplace Combustion of Wood, Environ. Sci. Technol., 9, 1716-1728, 2001.

Schlesinger, R. B.: Comparative deposition of inhaled aerosols in experimental animals and humans: a review, J. Toxicol. Environ. Health A, 2, 197-214, 1985.

Seinfeld, J. H. and Pandis, S. N.: Atmospheric chemistry and physics: from air pollution to climate change, John Wiley \& Sons, New York, USA, 2012.

Sen, A., Mandal, T. K., Sharma, S. K., Saxena, M., Gupta, N. C., Gautam, R., Gupta, A., Gill, T., Rani, S., Saud, T., Singh, D., and Gadi, R.: Chemical properties of emission from biomass fuels used in the rural sector of the western region of India, Atmos. Environ., 99, 411-424, 2014.

Shi, Y., Chen, J., Hu, D., Wang, L., Yang, X., and Wang, X.: Airborne submicron particulate $\left(\mathrm{PM}_{1}\right)$ pollution in Shanghai, China: Chemical variability, formation/dissociation of associated semivolatile components and the impacts on visibility, Sci. Total. Environ., 473-474, 199-206, 2014.

Shindell, D., Kuylenstierna, J. C. I., Vignati, E., van Dingenen, R., Amann, M., Klimont, Z., Anenberg, S. C., Muller, N., JanssensMaenhout, G., Raes, F., Schwartz, J., Faluvegi, G., Pozzoli, L., Kupiainen, K., Hoglund-Isaksson, L., Emberson, L., Streets, D., Ramanathan, V., Hicks, K., Oanh, N., Milly, G., Williams, M., Demkin, V., and Fowler, D.: Simultaneously Mitigating NearTerm Climate Change and Improving Human Health and Food Security, Science, 6065, 183-189, 2012.

Simcik, M. F., Eisenreich, S. J., and Lioy, P. J.: Source apportionment and source/sink relationships of PAHs in the coastal atmosphere of Chicago and Lake Michigan, Atmos. Environ., 30, 5071-5079, 1999.

Simoneit, B. R. T., Rushdi, A. I., Bin Abas, M. R., and Didyk, B. M.: Alkyl Amides and Nitriles as Novel Tracers for Biomass Burning, Environ. Sci. Technol., 1, 16-21, 2003.

Streets, D. G.: Dissecting future aerosol emissions: Warming tendencies and mitigation opportunities, Climatic Change, 3-4, 313-330, 2007.

Sun, J., Peng, H., Chen, J., Wang, X., Wei, M., Li, W., Yang, L., Zhang, L., Wang, W., and Mellouki, A.: An estimation of $\mathrm{CO}_{2}$ emission via agricultural crop residue open field burning in China from 1996 to 2013, J. Clean Prod., 112, 2625-2631, 2016.

Takegawa, N., Miyakawa, T., Kawamura, K., and Kondo, Y.: Contribution of Selected Dicarboxylic and $\omega$-Oxocarboxylic Acids in Ambient Aerosol to the $m / z 44$ Signal of an Aerodyne Aerosol Mass Spectrometer, Aerosol Sci. Tech., 41, 418-437, 2007.

Tao, Y., Ye, X., Jiang, S., Yang, X., Chen, J., Xie, Y., and Wang, R.: Effects of amines on particle growth observed in new particle formation events, J. Geophys. Res.-Atmos., 121, 324-335, doi:10.1002/2015JD024245, 2016.

Tian, D., Hu, Y., Wang, Y., Boylan, J. W., Zheng, M., and Russell, A. G.: Assessment of Biomass Burning Emissions and Their Im- 
pacts on Urban and Regional $\mathrm{PM}_{2.5}$ : A Georgia Case Study, Environ Sci. Technol., 2, 299-305, 2008.

Tóth, A., Hoffer, A., Nyiro-Kósa, I., Pósfai, M., and Gelencsér, A.: Atmospheric tar balls: aged primary droplets from biomass burning?, Atmos. Chem. Phys., 14, 6669-6675, doi:10.5194/acp-146669-2014, 2014.

Tsai, P. J., Shieh, H. Y., Lee, W. J., and Lai, S. O.: Health-risk assessment for workers exposed to polycyclic aromatic hydrocarbons (PAHs) in a carbon black manufacturing industry, Sci. Total. Environ., 1-3, 137-150, 2001.

Urban, R. C., Alves, C. A., Allen, A. G., Cardoso, A. A., and Campos, M.: Organic aerosols in a Brazilian agro-industrial area: Speciation and impact of biomass burning, Atmos. Res., 169, 271-279, 2016.

Veres, P., Roberts, J. M., Burling, I. R., Warneke, C., de Gouw, J., and Yokelson, R. J.: Measurements of gas-phase inorganic and organic acids from biomass fires by negative-ion proton-transfer chemical-ionization mass spectrometry, J. Geophys. Res., 115, D23302, doi:10.1029/2010JD014033, 2010.

Wang, L., Li, X., and Xu, Y.: The Economic Losses Caused By Crop Residues Burnt in Open Field in China, J. Arid Land Resour. Environ., 2, 170-175, 2008.

Wang, R., Tao, S., Wang, W., Liu, J., Shen, H., Shen, G., Wang, B., Liu, X., Li, W., Huang, Y., Zhang, Y., Lu, Y., Chen, H., Chen, Y., Wang, C., Zhu, D., Wang, X., Li, B., Liu, W., Ma, J., and Prospero, A.: Black carbon emissions in China from 1949 to 2050, Environ. Sci. Technol., 14, 7595-7603, 2012.

Wang, S. and Zhang, C.: Spatial and temporal distribution of air pollutant emissions from open burning of crop residues in China, Science, 5, 329-333, 2008.

Wang, S., Zhao, M., Xing, J., Wu, Y., Zhou, Y., Lei, Y., He, K., Fu, L., and Hao, J.: Quantifying the air pollutants emission reduction during the 2008 Olympic Games in Beijing, Environ. Sci. Technol., 7, 2490-2496, 2010.

Wang, W., Jariyasopit, N., Schrlau, J., Jia, Y., Tao, S., Yu, T., Dashwood, R. H., Zhang, W., Wang, X., and Simonich, S.: Concentration and photochemistry of PAHs, NPAHs, and OPAHs and toxicity of $\mathrm{PM}_{2.5}$ during the Beijing Olympic Games, Environ. Sci. Technol., 16, 6887-6895, 2011.

Wei, B. and Yang, L.: A review of heavy metal contaminations in urban soils, urban road dusts and agricultural soils from China, Microchem. J., 2, 99-107, 2010.

Wei, W., Jitao, Y., Qingling, Z., and Bailiang, Z.: Current Situation and Developing Direction of Straw Utilization Technology in China, China Resour. Comprehen. Utiliz., 7, 011, 2004.

WHO: Life Database in 2000, World Health Organization, Geneva, 2000.

Wilson, J. M., Baeza-Romero, M. T., Jones, J. M., Pourkashanian, M., Williams, A., Lea-Langton, A. R., Ross, A. B., and Bartle, K.: Soot Formation from the Combustion of Biomass Pyrolysis Products and a Hydrocarbon Fuel, n-Decane: An Aerosol Time Of Flight Mass Spectrometer (ATOFMS) Study, Energy Fuel, 3, 1668-1678, 2013.

Wong, C., Vichit-Vadakan, N., Kan, H., Qian, Z., and Teams, T. P. P.: Public Health and Air Pollution in Asia (PAPA): A Multicity Study of Short-Term Effects of Air Pollution on Mortality, Environ. Health Persp., 9, 1195-1202, 2008.
Wu, C., Wu, S., Wu, Y., Cullen, A. C., Larson, T. V., Williamson, J., and Liu, L. J. S.: Cancer risk assessment of selected hazardous air pollutants in Seattle, Environ Int., 3, 516-522, 2009.

Wu, C., Liu, L. J. S., Cullen, A., Westberg, H., and Williamson, J.: Spatial-temporal and cancer risk assessment of selected hazardous air pollutants in Seattle, Environ. Int., 1, 11-17, 2011.

$\mathrm{Xu}, \mathrm{S}$., Liu, W., and Tao, S.: Emission of Polycyclic Aromatic Hydrocarbons in China, Environ Sci. Technol., 3, 702-708, 2006.

Yang, C., Peng, X., Huang, W., Chen, R., Xu, Z., Chen, B., and Kan, H.: A time-stratified case-crossover study of fine particulate matter air pollution and mortality in Guangzhou, China, Int. Arch. Occ. Environ. Health, 5, 579-585, 2012.

Yang, M., Howell, S. G., Zhuang, J., and Huebert, B. J.: Attribution of aerosol light absorption to black carbon, brown carbon, and dust in China - interpretations of atmospheric measurements during EAST-AIRE, Atmos. Chem. Phys., 6, 2035-2050, doi:10.5194/acp-9-2035-2009, 2009.

Yang, Y., Liu, X., Qu, Y., Wang, J., An, J., Zhang, Y., and Zhang, F.: Formation mechanism of continuous extreme haze episodes in the megacity Beijing, China, in January 2013, Atmos. Res., 155, 192-203, 2015.

Yokelson, R. J., Karl, T., Artaxo, P., and Blake, D. R.: The Tropical Forest and Fire Emissions Experiment: overview and airborne fire emission factor measurements, Atmos. Chem. Phys., 7, 5175-5196, doi:10.5194/acp-7-5175-2007, 2007.

Yunker, M. B., Macdonald, R. W., Vingarzan, R., Mitchell, R. H., Goyette, D., and Sylvestre, S.: PAHs in the Fraser River basin: a critical appraisal of $\mathrm{PAH}$ ratios as indicators of PAH source and composition, Org. Geochem., 4, 489-515, 2002.

Zhang, H., Hu, D., Chen, J., Ye, X., Wang, S. X., Hao, J. M., Wang, L., Zhang, R., and An, Z.: Particle Size Distribution and Polycyclic Aromatic Hydrocarbons Emissions from Agricultural Crop Residue Burning, Environ. Sci. Technol., 13, 5477-5482, 2011.

Zhang, H., Wang, S., Hao, J., Wan, L., Jiang, J., Zhang, M., Mestl, H. E., Mestl, H., Alnes, L., Aunan, K., and Mellouki, A.: Chemical and size characterization of particles emitted from the burning of coal and wood in rural households in Guizhou, China, Atmos. Environ., 51, 94-99, 2012.

Zhang, H., Ye, X., Cheng, T., Chen, J., Yang, X., Wang, L., and Zhang, R.: A laboratory study of agricultural crop residue combustion in China: Emission factors and emission inventory, Atmos. Environ., 36, 8432-8441, 2008.

Zhang, R., Suh, I., Zhao, J., Zhang, D., Fortner, E. C., Tie, X., Molina, L. T., and Molina, M. J.: Atmospheric new particle formation enhanced by organic acids, Science, 5676, 1487-1490, 2004.

Zhang, R., Khalizov, A. F., Pagels, J., Zhang, D., Xue, H., and McMurry, P. H.: Variability in morphology, hygroscopicity, and optical properties of soot aerosols during atmospheric processing, P. Natl. Acad. Sci. USA, 30, 10291-10296, 2008.

Zhao, B., Wang, P., Ma, J. Z., Zhu, S., Pozzer, A., and Li, W.: A high-resolution emission inventory of primary pollutants for the Huabei region, China, Atmos. Chem. Phys., 12, 481-501, doi:10.5194/acp-12-481-2012, 2012.

Zhao, Y., Nielsen, C. P., Lei, Y., McElroy, M. B., and Hao, J.: Quantifying the uncertainties of a bottom-up emission inventory of anthropogenic atmospheric pollutants in China, Atmos. Chem. Phys., 11, 2295-2308, doi:10.5194/acp-11-2295-2011, 2011. 
Zheng, J., Ma, Y., Chen, M., Zhang, Q., Wang, L., Khalizov, A. F., Yao, L., Wang, Z., Wang, X., and Chen, L.: Measurement of atmospheric amines and ammonia using the high resolution timeof-flight chemical ionization mass spectrometry, Atmos. Environ., 102, 249-259, 2015. 